\title{
An analytical model for wind-driven Arctic summer sea ice drift
}

\author{
H.-S. Park ${ }^{1}$ and A. L. Stewart ${ }^{2}$ \\ ${ }^{1}$ Korea Institute of Geoscience and Mineral Resources, Daejeon, South Korea \\ ${ }^{2}$ Department of Atmospheric and Oceanic Sciences, University of California, Los Angeles, USA
}

Correspondence to: H.-S. Park (hspark1 @ gmail.com)

Received: 12 January 2015 - Published in The Cryosphere Discuss.: 27 March 2015

Revised: 28 November 2015 - Accepted: 16 December 2015 - Published: 21 January 2016

\begin{abstract}
The authors present an analytical model for winddriven free drift of sea ice that allows for an arbitrary mixture of ice and open water. The model includes an ice-ocean boundary layer with an Ekman spiral, forced by transfers of wind-input momentum both through the sea ice and directly into the open water between the ice floes. The analytical tractability of this model allows efficient calculation of the ice velocity provided that the surface wind field is known and that the ocean geostrophic velocity is relatively weak. The model predicts that variations in the ice thickness or concentration should substantially modify the rotation of the velocity between the $10 \mathrm{~m}$ winds, the sea ice, and the ocean.

Compared to recent observational data from the first icetethered profiler with a velocity sensor (ITP-V), the model is able to capture the dependencies of the ice speed and the wind/ice/ocean turning angles on the wind speed. The model is used to derive responses to intensified southerlies on Arctic summer sea ice concentration, and the results are shown to compare closely with satellite observations.
\end{abstract}

\section{Introduction}

The drift of Arctic sea ice is largely explained by surface winds and upper-ocean currents. The effect of the mean geostrophic upper-ocean currents on the average circulation of sea ice pack is known to be as important as the mean wind field (Thorndike and Colony, 1982). However, the role of the winds becomes increasingly important over shorter timescales: on timescales from days to months, surface wind variability explains more than $70 \%$ of the sea ice motion (Thorndike and Colony, 1982) and is well correlated with the surface ocean velocity (Cole et al., 2014). The synoptic eddy surface winds result in a primary mode of upper-ocean velocity variability with a period of 2-5 days over the icecovered Arctic Ocean (Plueddemann et al., 1998). The tight connection between surface winds and upper-ocean velocity over ice-covered Arctic Ocean suggests that resolving the wind-induced surface Ekman flow is essential for simulating sea ice motions.

Many simple sea ice models assume steady ocean currents and prescribe a quadratic relationship with an empirically chosen turning angle between the ice stress and surface ocean velocity (Hibler III, 1979; Thorndike and Colony, 1982; Bitz et al., 2002; Uotila et al., 2012). This model configuration has limitations in simulating wind-induced sea ice drift on intraseasonal timescales, during which time-varying Ekman layer flows in the ice-ocean boundary layer (IOBL) may be important. The effect of the surface Ekman flow on sea ice motion can be resolved by coupling the sea ice model to a comprehensive ocean model (Zhang and Rothrock, 2003; Uotila et al., 2012). However, such an approach is computationally expensive and makes it difficult to disentangle the physical processes controlling sea ice drift.

In the past few decades, considerable advances have been made in understanding the physics of the IOBL, notably via the development of Rossby similarity theory (McPhee, 1979, 1981, 1994, 2008). In the case of an unstratified surface layer, this theory connects the ocean's Ekman layer to the ice base via a thin surface layer in which the velocity shear follows the "law of the wall" and the vertical eddy viscosity varies linearly to 0 . In contrast to frequently used quadratic drag parameterizations (e.g., Hibler III, 1979; Thorndike and Colony, 1982), this results in a quadratic drag coefficient and turning angle that depend on the stress velocity and the hydraulic roughness length of the ice base. However, the assumptions underlying Rossby similarity theory make it inap- 
plicable to the case of a mixture of sea ice and open water, which is typical of the Arctic in summer.

In Sect. 2 we derive an approximate analytical model for wind-induced sea ice drift that accounts for the Ekman spiral in the IOBL and allows for an arbitrary mixture of ice and water but neglects internal stress within the ice. The model is therefore most appropriate to the marginal ice zone, which covers much of the Arctic during summer. This approach has both theoretical and practical merits: because the Ekman layer is resolved in the momentum balance, the turning angle is a prognostic variable in our model, allowing us to explore the dependence of both the ice drift speed and the wind/ice/ocean turning angles on the concentration and thickness of the sea ice. The analytical tractability of the model allows efficient calculation of the sea ice drift, certainly much more so than running a fully coupled model of the Arctic. We compare our model's predictions against observations of Arctic sea ice concentration (SIC) and velocity: the data sources and reanalysis products used for this purpose are described in Sect. 3.

In Sect. 4, we evaluate our model against recent observations from an ice-tethered profiler (Cole et al., 2014), focusing on the angles between the wind and ice velocities and between the ice and ocean velocities. At face value our model may not appear to be applicable to these data because the measurements were made in the Beaufort Sea in winter, when the SIC is close to $100 \%$ and internal stress is likely to be dynamically significant (Leppäranta, 2005). However, the analysis of Cole et al. (2014) suggests that the ice floe velocity was in fact close to a free drift regime and that the vertical buoyancy flux in the IOBL was small compared to previous winter observations (see, e.g., McPhee, 2008). Consequently, our model largely captures the dependence of the ice speed and turning angle on the surface wind speed.

In Sect. 5 we apply our model to predict the anomalous change in Arctic SIC associated with intraseasonal intensification of the southerly winds in the Pacific sector. This serves a dual purpose. First, it is a test of our model's assumptions that the summer sea ice drift can be described accurately by neglecting internal stresses and assuming constant drag coefficients at the ice-ocean, atmosphere-ice, and atmosphereocean interfaces. Second, by extension, it tests the hypothesis that the anomalous reduction in SIC in the Pacific sector during southerly wind events can be attributed to the mechanical effect of wind-driven ice drift rather than thermodynamic effects. Many previous observational analyses provided only statistical connections between the southerly winds and sea ice cover. For example, the strength of southwesterlies over the Barents Sea is well correlated with sea ice cover in winter (Sorteberg and Kvingedal, 2006; Liptak and Strong, 2014), and the development of anomalous southerlies over the Pacific sector of the Arctic is often followed by a reduction of sea ice cover in the spring and summer (Wu et al., 2006; Serreze et al., 2003). We demonstrate that the southerly wind-induced sea ice advection, accelerated by wind-induced surface Ekman flow, can substantially decrease SIC over a timescale of 1 week.

\section{An analytical model for wind-driven sea ice motion}

In this section we employ a simplified sea ice model to obtain analytical expressions for the sea ice velocity as a function of surface wind speed. In Sect. 2.1 we formulate an approximate sea ice momentum balance appropriate for basin-scale motions, and then in Sect. 2.2 we derive an analytical solution for the sea ice velocity, assuming that the surface wind speed is known.

\subsection{Model formulation}

We employ a "mixture layer" model of Arctic sea ice (Gray and Morland, 1994), which describes the evolution of ice floes interspersed with patches of open water. The thicknessintegrated momentum balance for such a mixture layer may be written as (Heorton et al., 2014)

$\rho_{\mathrm{i}} h_{\mathrm{i}} \frac{\mathrm{D} \boldsymbol{u}_{\mathrm{i}}}{\mathrm{D} t}=\varphi\left(\boldsymbol{\tau}_{\text {ai }}-\boldsymbol{\tau}_{\text {io }}\right)-\rho_{\mathrm{i}} h_{\mathrm{i}} f\left(\hat{\boldsymbol{Z}} \times \boldsymbol{u}_{\mathrm{i}}\right)-\rho_{\mathrm{i}} h_{\mathrm{i}} g \nabla \eta+\nabla \cdot \sigma$,

where $h_{\mathrm{i}}$ is the ice thickness, $\rho_{\mathrm{i}}$ is the ice density, $\boldsymbol{u}_{\mathrm{i}}$ is the ice velocity vector, $\eta$ is the sea surface height, $\varphi$ is the sea ice fraction, $f$ is the Coriolis parameter, $g$ is the acceleration due to gravity, and $\hat{\boldsymbol{Z}}$ is a vertical unit vector. Equation (1) states that the ice/water mixture layer is accelerated by momentum exchanges between the ice and the atmosphere ( $\left.\boldsymbol{\tau}_{\mathrm{ai}}\right)$ and between the ice and the ocean ( $\left.\boldsymbol{\tau}_{\text {io }}\right)$, by the Coriolis force, by horizontal pressure variations due to sea surface tilt, and by the divergence of a stress tensor $(\sigma)$ representing internal stress in the ice.

We first write the lateral pressure gradient term in terms of the ocean near-surface geostrophic velocity $\boldsymbol{u}_{\mathrm{g}}$ :

$$
f \hat{\boldsymbol{Z}} \times \boldsymbol{u}_{\mathrm{g}}=\rho_{\mathrm{i}} h_{\mathrm{i}} g \nabla \eta .
$$

We are concerned with sea ice evolution over a typical timescale of 1 week with a velocity scale of around $0.2 \mathrm{~m} \mathrm{~s}^{-1}$, implying a length scale of around $100 \mathrm{~km}$. The ice acceleration term in Eq. (1) may therefore be safely neglected (McPhee, 1980; Thorndike and Colony, 1982). This precludes the sea ice undergoing inertial oscillations, though the diameter of such oscillations would only be a few kilometers at most, much smaller than the drift length scale of $100 \mathrm{~km}$. In summer, the Arctic SIC is mostly below $80 \%$ (see Fig. 1), so away from coastal shear margins the internal friction term in Eq. (1) is also negligible (Leppäranta, 2005; Kawaguchi and Mitsudera, 2008). This simplifies the momentum balance to

$\rho_{\mathrm{i}} h_{\mathrm{i}} f \hat{\boldsymbol{Z}} \times\left(\boldsymbol{u}_{\mathrm{i}}-\boldsymbol{u}_{\mathrm{g}}\right)=\varphi\left(\boldsymbol{\tau}_{\text {ai }}-\boldsymbol{\tau}_{\text {io }}\right)$.

Similar scaling arguments suggest that the pressure gradient due to the sea surface tilt may also be negligible. For now 


\section{(a) Sea-ice thickness (Oct - Mar)}

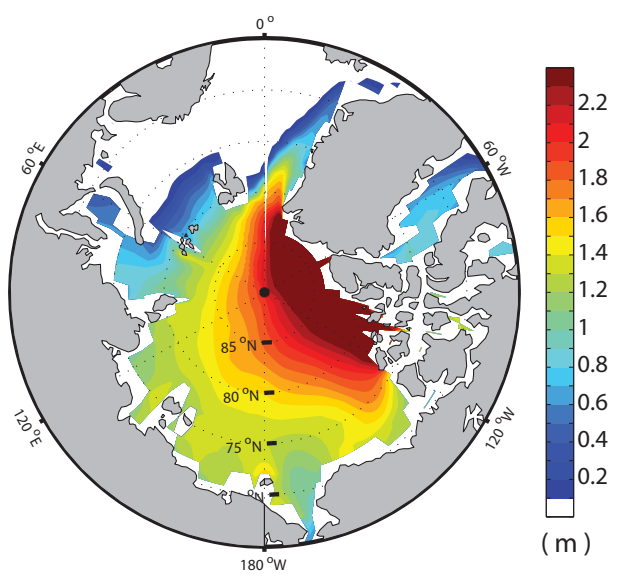

(b) Sea-ice concentration (Oct-Mar)

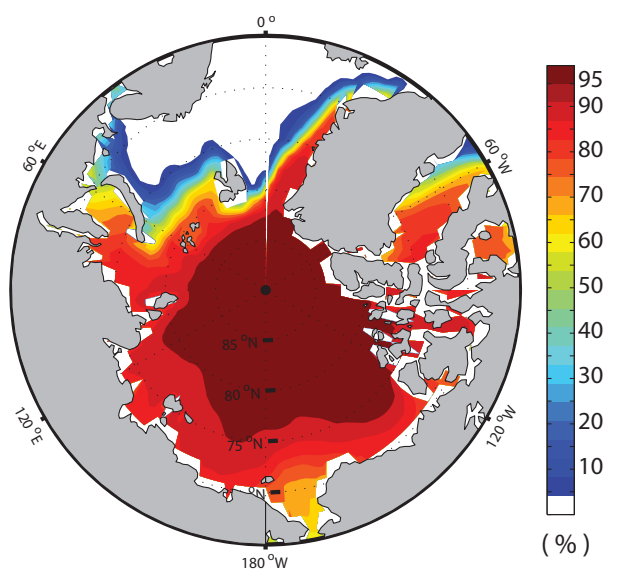

Figure 1. (a) Sea ice thickness (a) and (b) sea ice concentration (\%), averaged from October 2009 to March 2010. Sea ice thickness is from PIOMAS and sea ice concentration data are from NSDIC.

we retain this term because it is analytically tractable, but in Sects. 4 and 5 below we will neglect the geostrophic ocean velocity term in Eq. (3).

Equation (3) states that the shear between the mixture layer and the ocean's surface geostrophic velocity, or equivalently the total shear across the IOBL (McPhee, 2012), lies perpendicular to the vertical stress divergence in the sea ice. This equation does not account for momentum imparted from the winds to the water between the ice floes in the mixture layer, which is assumed to be transferred directly to the ocean below (Gray and Morland, 1994). The total stress felt by the ocean at the base of the mixture layer is therefore

$\boldsymbol{\tau}_{\mathrm{o}}=(1-\varphi) \boldsymbol{\tau}_{\mathrm{ao}}+\varphi \boldsymbol{\tau}_{\mathrm{io}}$,

where $\boldsymbol{\tau}_{\text {ao }}$ is the momentum imparted to the ocean from the atmosphere between the sea ice floes. We adopt an approach similar to Rossby similarity theory for the IOBL, assuming that the ocean velocity follows an Ekman spiral beneath the mixture layer (McPhee, 2012). The ocean velocity at the top of the Ekman layer is therefore given as

$\boldsymbol{u}_{\mathrm{o}}-\boldsymbol{u}_{\mathrm{g}}=\frac{1}{\sqrt{2 K_{\mathrm{o}}^{*}}}\left(\boldsymbol{u}_{\mathrm{o}}^{*}-\hat{\boldsymbol{Z}} \times \boldsymbol{u}_{\mathrm{o}}^{*}\right)$,

where $K_{\mathrm{o}}^{*}=K f /\left|\boldsymbol{u}_{\mathrm{o}}^{*}\right|^{2}$ is the dimensionless vertical eddy diffusivity, $K$ is the dimensional vertical eddy diffusivity, $\boldsymbol{u}_{\mathrm{o}}^{*}$ is the stress velocity defined by $\boldsymbol{\tau}_{\mathrm{o}}=\rho_{\mathrm{o}}\left|\boldsymbol{u}_{\mathrm{o}}^{*}\right| \boldsymbol{u}_{\mathrm{o}}^{*}$, and $\rho_{\mathrm{o}}$ is the ocean surface density. The dimensionless diffusivity $K_{\mathrm{o}}^{*}$ is taken to be constant, reflecting a linear dependence of the Ekman layer depth on the stress velocity. This is appropriate for IOBLs with no surface buoyancy forcing; non-zero surface buoyancy modifies the vertical profile of $K$ in the IOBL (McPhee, 2008). Our model could be extended to accommodate an arbitrary $K$ profile if the surface buoyancy fluxes were known, but for simplicity in this study we assume zero surface buoyancy forcing. We prescribe the air-ice, airocean, and ice-ocean stresses using quadratic drag relations:

$\boldsymbol{\tau}_{\mathrm{ai}}=\rho_{\mathrm{a}} C_{\mathrm{ai}}\left|\boldsymbol{u}_{\mathrm{a}}\right| \boldsymbol{u}_{\mathrm{a}}=\rho_{\mathrm{a}}\left|\boldsymbol{u}_{\mathrm{ai}}^{*}\right| \boldsymbol{u}_{\mathrm{ai}}^{*}$,

$\boldsymbol{\tau}_{\mathrm{ao}}=\rho_{\mathrm{a}} C_{\mathrm{ao}}\left|\boldsymbol{u}_{\mathrm{a}}\right| \boldsymbol{u}_{\mathrm{a}}=\rho_{\mathrm{a}}\left|\boldsymbol{u}_{\mathrm{ao}}^{*}\right| \boldsymbol{u}_{\mathrm{ao}}^{*}$,

$\boldsymbol{\tau}_{\text {io }}=\rho_{\mathrm{o}} C_{\mathrm{io}}\left|\boldsymbol{u}_{\mathrm{i}}-\boldsymbol{u}_{\mathrm{o}}\right|\left(\boldsymbol{u}_{\mathrm{i}}-\boldsymbol{u}_{\mathrm{o}}\right)=\rho_{\mathrm{o}}\left|\boldsymbol{u}_{\mathrm{io}}^{*}\right| \boldsymbol{u}_{\mathrm{io}}^{*}$,

where $\rho_{\mathrm{a}}$ and $\rho_{\mathrm{o}}$ are the atmospheric and surface ocean density, respectively. Here we have implicitly assumed that there exist thin turbulent boundary layers between the atmosphere and the ice floes, between the atmosphere and ocean leads, and between the bases of the ice floes and the top of the Ekman layer, each of which transfers momentum at a rate that varies quadratically with the vertical shear. We have further assumed that any momentum imparted to the ocean leads is transferred directly down to the Ekman layer below. More comprehensive treatments of the ice-ocean stress may be derived using Rossby similarity theory (McPhee, 2008, 2012). However, this theory cannot be applied in the presence of leads between the sea ice floes, which continually change the surface boundary condition at any given point between a free surface and a rigid ice floe. In many previous studies, these stresses carry a turning angle to account for the effect of the Coriolis force in the boundary layer (Hibler III, 1979; Thorndike and Colony, 1982; Bitz et al., 2002; Uotila et al., 2012). This is not necessary here because we use the ageostrophic $10 \mathrm{~m}$ winds, and we explicitly account for the ocean surface Ekman layer.

By combining the ice-ocean stress relation Eq. (6c), which can be rewritten as $\boldsymbol{u}_{\mathrm{io}}^{*}=\sqrt{C_{\mathrm{io}}}\left(\boldsymbol{u}_{\mathrm{i}}-\boldsymbol{u}_{\mathrm{o}}\right)$, with Eq. (5) for the shear across the Ekman layer, we obtain an expression for the total shear across the IOBL:

$\boldsymbol{u}_{\mathrm{i}}-\boldsymbol{u}_{\mathrm{g}}=\frac{1}{\sqrt{C_{\mathrm{io}}}} \boldsymbol{u}_{\mathrm{io}}^{*}+\frac{1}{\sqrt{2 K_{0}^{*}}}\left(\boldsymbol{u}_{\mathrm{o}}^{*}-\hat{\boldsymbol{Z}} \times \boldsymbol{u}_{\mathrm{o}}^{*}\right)$.

Then, substituting Eqs. (6a), (6c), and (7) into the momentum balance Eq. (3), we obtain a relationship between the unknown stress velocities $\boldsymbol{u}_{\mathrm{io}}^{*}$ and $\boldsymbol{u}_{\mathrm{o}}^{*}$ : 


$$
\begin{aligned}
\frac{\rho_{\mathrm{i}} h_{\mathrm{i}} f}{\sqrt{C_{\mathrm{io}}}} \hat{\boldsymbol{Z}} & \times \boldsymbol{u}_{\mathrm{io}}^{*}+\frac{\rho_{\mathrm{i}} h_{\mathrm{i}} f}{\sqrt{2 K_{0}^{*}}}\left(\hat{\boldsymbol{Z}} \times \boldsymbol{u}_{\mathrm{o}}^{*}+\boldsymbol{u}_{\mathrm{o}}^{*}\right) \\
= & \varphi\left(\rho_{\mathrm{a}}\left|\boldsymbol{u}_{\mathrm{ai}}^{*}\right| \boldsymbol{u}_{\mathrm{ai}}^{*}-\rho_{\mathrm{o}}\left|\boldsymbol{u}_{\mathrm{io}}^{*}\right| \boldsymbol{u}_{\mathrm{io}}^{*}\right) .
\end{aligned}
$$

We require an additional equation to obtain an explicit solution for $\boldsymbol{u}_{\mathrm{io}}^{*}$ and $\boldsymbol{u}_{\mathrm{o}}^{*}$, so we rewrite the total stress at the base of the mixing layer Eq. (4) in the form

$\rho_{\mathrm{o}}\left|\boldsymbol{u}_{\mathrm{o}}^{*}\right| \boldsymbol{u}_{\mathrm{o}}^{*}=(1-\varphi) \rho_{\mathrm{a}}\left|\boldsymbol{u}_{\mathrm{ao}}^{*}\right| \boldsymbol{u}_{\mathrm{ao}}^{*}+\varphi \rho_{\mathrm{o}}\left|\boldsymbol{u}_{\mathrm{io}}^{*}\right| \boldsymbol{u}_{\mathrm{io}}^{*}$.

\subsection{Model solution}

In order to derive a solution for the ice velocity $\boldsymbol{u}_{\mathrm{i}}$, we now solve the previously derived Eqs. (8) and (9) for the stress velocities $\boldsymbol{u}_{\mathrm{io}}^{*}$ and $\boldsymbol{u}_{\mathrm{o}}^{*}$.

\subsubsection{Near-100 \% sea ice cover $(\varphi \approx 1)$}

We first consider the case of close-to- $100 \%$ sea ice cover $(\varphi \approx 1)$ because this permits a closed-form analytical solution that offers physical intuition for the behavior of the model. Though an actual SIC of $100 \%$ would likely be associated with large internal stresses, we use it for the purpose of illustration because our results in Sect. 4 indicate that this closely approximates the general solution for ice concentrations greater than $50 \%$. The method of solution is similar to that described by Leppäranta (2005), Sect. 6.1, but our explicit treatment of the oceanic boundary layer and prognostic determination of the turning angle warrant that the solution be described explicitly.

For SICs close to $100 \%(\varphi \approx 1)$ Eq. (9) implies that the ice-ocean and ocean surface stress velocities are approximately equal, $\boldsymbol{u}_{\mathrm{io}}^{*} \approx \boldsymbol{u}_{\mathrm{o}}^{*}$. Thus Eqs. (7) and (8) may be rewritten as

$$
\begin{aligned}
& \boldsymbol{u}_{\mathrm{i}}-\boldsymbol{u}_{\mathrm{g}}=\left(\frac{1}{\sqrt{C_{\mathrm{io}}}}+\frac{1}{\sqrt{2 K_{0}^{*}}}\right) \boldsymbol{u}_{\mathrm{io}}^{*}-\frac{1}{\sqrt{2 K_{0}^{*}}} \hat{\boldsymbol{Z}} \times \boldsymbol{u}_{\mathrm{io}}^{*} \\
& \left(\frac{\rho_{\mathrm{i}} h_{\mathrm{i}} f}{\sqrt{2 K_{0}^{*}}}+\frac{\rho_{\mathrm{i}} h_{\mathrm{i}} f}{\sqrt{C_{\mathrm{io}}}}\right) \hat{\boldsymbol{z}} \times \boldsymbol{u}_{\mathrm{io}}^{*}+\frac{\rho_{\mathrm{i}} h_{\mathrm{i}} f}{\sqrt{2 K_{0}^{*}}} \boldsymbol{u}_{\mathrm{io}}^{*} \\
& =\rho_{\mathrm{a}}\left|\boldsymbol{u}_{\mathrm{ai}}^{*}\right| \boldsymbol{u}_{\mathrm{ai}}^{*}-\rho_{\mathrm{o}}\left|\boldsymbol{u}_{\mathrm{io}}^{*}\right| \boldsymbol{u}_{\mathrm{io}}^{*} .
\end{aligned}
$$

We simplify the coefficients by multiplying both sides of Eq. (10b) by $\sqrt{2 K_{0}^{*}} / \rho_{\mathrm{i}} h_{\mathrm{i}} f$ and rearranging to obtain

$(\alpha+1) \hat{\boldsymbol{Z}} \times \boldsymbol{u}_{\mathrm{io}}^{*}+\left(1+k_{\mathrm{o}}\left|\boldsymbol{u}_{\mathrm{io}}^{*}\right|\right) \boldsymbol{u}_{\mathrm{io}}^{*}=k_{\mathrm{a}}\left|\boldsymbol{u}_{\mathrm{ai}}^{*}\right| \boldsymbol{u}_{\mathrm{ai}}^{*}$,

where

$$
\begin{aligned}
\alpha & =\sqrt{2 K_{0}^{*} / C_{\mathrm{io}}}, k_{\mathrm{a}}=\rho_{\mathrm{a}} \sqrt{2 K_{0}^{*}} / \rho_{\mathrm{i}} h_{\mathrm{i}} f \text { and } k_{\mathrm{o}} \\
& =\rho_{\mathrm{o}} \sqrt{2 K_{0}^{*}} / \rho_{\mathrm{i}} h_{\mathrm{i}} f .
\end{aligned}
$$

To solve, we first define the components of $\boldsymbol{u}_{\mathrm{i}}^{*}$ parallel and perpendicular to the wind stress velocity or, equivalently, perpendicular the $10 \mathrm{~m}$ winds:

$$
\begin{aligned}
& u_{\mathrm{io}}^{* \|}=\frac{\boldsymbol{u}_{\mathrm{ai}}^{*}}{\left|\boldsymbol{u}_{\mathrm{ai}}^{*}\right|} \cdot \boldsymbol{u}_{\mathrm{io}}^{*}, \\
& u_{\mathrm{io}}^{* \perp}=\left(\hat{\boldsymbol{Z}} \times \frac{\boldsymbol{u}_{\mathrm{ai}}^{*}}{\left|\boldsymbol{u}_{\mathrm{ai}}^{*}\right|}\right) \cdot \boldsymbol{u}_{\mathrm{io}}^{*} .
\end{aligned}
$$

Then taking the dot product of $\boldsymbol{u}_{\mathrm{io}}^{*}$ with both sides of Eq. (11) and rearranging yields an expression for $u_{\mathrm{io}}^{* \|}$,

$u_{\mathrm{io}}^{* \|}=\frac{1}{k_{\mathrm{a}}} \frac{\left|\boldsymbol{u}_{\mathrm{io}}^{*}\right|^{2}}{\left|\boldsymbol{u}_{\mathrm{ai}}^{*}\right|^{2}}\left(1+k_{\mathrm{o}}\left|\boldsymbol{u}_{\mathrm{io}}^{*}\right|\right)$,

while taking the dot product of $\hat{\boldsymbol{Z}} \times \boldsymbol{u}_{\mathrm{i}}^{*}$ with both sides of Eq. (11) yields an expression for $u_{\mathrm{io}}^{* \perp}$,

$u_{\mathrm{io}}^{* \perp}=-\frac{1}{k_{\mathrm{a}}} \frac{\left|\boldsymbol{u}_{\mathrm{io}}^{*}\right|^{2}}{\left|\boldsymbol{u}_{\mathrm{ai}}^{*}\right|^{2}}(1+\alpha)$.

Equations (14) and (15) do not constitute an explicit solution for $\boldsymbol{u}_{\mathrm{io}}^{*}$ because they depend on its magnitude $\left|\boldsymbol{u}_{\mathrm{io}}^{*}\right|$. We determine this magnitude using the definition, $\left|\boldsymbol{u}_{\mathrm{io}}^{*}\right|^{2}=\left(u_{\mathrm{io}}^{* \|}\right)^{2}+\left(u_{\mathrm{io}}^{* \perp}\right)^{2}$, which yields a quartic equation for $\left|\boldsymbol{u}_{\mathrm{io}}^{*}\right|:$

$k_{\mathrm{o}}^{2}\left|\boldsymbol{u}_{\mathrm{io}}^{*}\right|^{4}+2 k_{\mathrm{o}}\left|\boldsymbol{u}_{\mathrm{io}}^{*}\right|^{3}+\left(1+(\alpha+1)^{2}\right)\left|\boldsymbol{u}_{\mathrm{io}}^{*}\right|^{2}=k_{\mathrm{a}}^{2}\left|\boldsymbol{u}_{\mathrm{ai}}^{*}\right|^{4}$.

In principle, this may be solved analytically for $\left|\boldsymbol{u}_{\mathrm{i}}^{*}\right|$, but for the purposes of this study we solve Eq. (16) numerically. Note that the left-hand side of Eq. (16) is a monotonically increasing function of $\left|\boldsymbol{u}_{\mathrm{io}}^{*}\right|$, so a unique solution exists for any wind stress velocity magnitude $\left|\boldsymbol{u}_{\mathrm{ai}}^{*}\right|$. Having obtained the components of the stress velocity, it is straightforward to solve for the shear between the sea ice and the geostrophic ocean velocity using Eq. (10a).

\subsubsection{Sparse sea ice cover $(\varphi \ll 1)$}

We now consider SICs much below $100 \%$. We begin by simplifying the coefficients in Eqs. (8) and (9) by defining $\alpha, k_{\mathrm{a}}$, and $k_{\mathrm{o}}$ as in Sect. 2.1 and additionally defining $\beta=\rho_{\mathrm{a}} C_{\mathrm{ao}} / \rho_{\mathrm{o}} C_{\mathrm{ai}}$ :

$\alpha \hat{\boldsymbol{Z}} \times \boldsymbol{u}_{\mathrm{io}}^{*}+\hat{\boldsymbol{Z}} \times \boldsymbol{u}_{\mathrm{o}}^{*}+\boldsymbol{u}_{\mathrm{o}}^{*}=\varphi k_{\mathrm{a}}\left|\boldsymbol{u}_{\mathrm{ai}}^{*}\right| \boldsymbol{u}_{\mathrm{ai}}^{*}-\varphi k_{\mathrm{o}}\left|\boldsymbol{u}_{\mathrm{io}}^{*}\right| \boldsymbol{u}_{\mathrm{io}}^{*}$,

$\left|\boldsymbol{u}_{\mathrm{o}}^{*}\right| \boldsymbol{u}_{\mathrm{o}}^{*}=(1-\varphi) \beta\left|\boldsymbol{u}_{\mathrm{ai}}^{*}\right| \boldsymbol{u}_{\mathrm{ai}}^{*}+\varphi\left|\boldsymbol{u}_{\mathrm{io}}^{*}\right| \boldsymbol{u}_{\mathrm{io}}^{*}$.

Here we have combined Eqs. (6a) and (6b) to relate the atmosphere-ice and atmosphere-ocean stress velocities via $\boldsymbol{u}_{\mathrm{ai}}^{*} / \sqrt{C_{\mathrm{ai}}}=\boldsymbol{u}_{\mathrm{ao}}^{*} / \sqrt{C_{\mathrm{ao}}}$. Equations (17)-(18) may in principle be solved analytically following a procedure similar to that described in Sect. 2.2.1: by defining stress velocity components parallel and perpendicular to the atmospheric velocity, $u_{\mathrm{io}}^{* \|}, u_{\mathrm{io}}^{* \perp}, u_{\mathrm{o}}^{* \|}$, and $u_{\mathrm{o}}^{* \perp}$, analogously to definitions Eqs. (13a) and (13b). Then taking the dot product of $\boldsymbol{u}_{\mathrm{ai}}^{*}$ and $\hat{\boldsymbol{Z}} \times \boldsymbol{u}_{\mathrm{ai}}^{*}$ with each of Eqs. (17) and (18) yields four scalar equations that can be solved simultaneously for the 
components of $\boldsymbol{u}_{\mathrm{io}}^{*}$ and $\boldsymbol{u}_{\mathrm{o}}^{*}$. Finally, using the definitions $\left|\boldsymbol{u}_{\mathrm{io}}^{*}\right|^{2}=\left(u_{\mathrm{io}}^{* \|}\right)^{2}+\left(u_{\mathrm{io}}^{* \perp}\right)^{2}$ and $\left|\boldsymbol{u}_{\mathrm{o}}^{*}\right|^{2}=\left(u_{\mathrm{o}}^{* \|}\right)^{2}+\left(u_{\mathrm{o}}^{* \perp}\right)^{2}$ yields a pair of equations that must be solved simultaneously for $\left|\boldsymbol{u}_{\mathrm{io}}^{*}\right|$ and $\left|\boldsymbol{u}_{\mathrm{o}}^{*}\right|$. However, this analytical solution is too complicated to yield physical insight, so in practice we simply solve Eqs. (17)-(18) numerically using least-squares optimization.

\subsection{Physical interpretation}

Though Eqs. (14)-(16) constitute an analytical solution to the mixture layer momentum balance Eq. (11), in this form they yield little insight into the wind-driven drift of sea ice. We therefore provide additional formulae for some key quantities describing the ice drift. Moreover, we briefly discuss the similarities and differences between our equations and the equations based on Rossby similarity theory (e.g., McPhee, 2008, 2012). We base our discussion around the solution for near-100\% SIC, given in Sect. 2.2.1, because this solution is completely analytical and thus offers more insight.

\subsubsection{Ice velocity}

For convenience we re-state Eq. (10a), which relates the shear between the ice and the geostrophic ocean velocity to the ice-ocean stress velocity in the case of close to $100 \%$ sea ice cover:

$\boldsymbol{u}_{\mathrm{i}}-\boldsymbol{u}_{\mathrm{g}}=\left(\frac{1}{\sqrt{C_{\mathrm{io}}}}+\frac{1}{\sqrt{2 K_{0}^{*}}}\right) \boldsymbol{u}_{\mathrm{io}}^{*}-\frac{1}{\sqrt{2 K_{0}^{*}}} \hat{\boldsymbol{Z}} \times \boldsymbol{u}_{\mathrm{io}}^{*}$.

This equation is similar to the one derived by McPhee (2008, 2012) for the case of an unstratified IOBL, because both approaches assume a traditional Ekman layer solution over most of the IOBL. However, there are some notable differences: instead of assuming that the turbulent transfer of momentum follows a quadratic drag law, McPhee $(2008,2012)$ utilized the law of the wall equation across the ocean-ice boundary layer, leading to a slightly more complicated version of this equation:

$$
\begin{aligned}
\boldsymbol{u}_{\mathrm{i}}-\boldsymbol{u}_{\mathrm{g}}= & \left(\frac{1}{\kappa} \log \left(\frac{\left|\boldsymbol{u}_{\mathrm{io}}^{*}\right|}{f z z_{0}}\right)+\frac{1}{\kappa} \log \left(\frac{K_{0}^{*}}{\kappa}\right)+\frac{1}{\sqrt{2 K_{0}^{*}}}\right) \\
& \boldsymbol{u}_{\mathrm{io}}^{*}-\frac{1}{\sqrt{2 K_{0}^{*}}} \hat{\boldsymbol{Z}} \times \boldsymbol{u}_{\mathrm{io}}^{*},
\end{aligned}
$$

where $\kappa$ is Kármán's constant $(\kappa=0.4)$ and $z_{0}$ is hydraulic roughness at the bottom of sea ice. Because the velocity profile over the ocean-ice boundary layer is assumed to be logarithmic (i.e., following the law of the wall), logarithmic terms appear as coefficients of ice-ocean stress velocity $\boldsymbol{u}_{\mathrm{io}}^{*}$. In our Eq. (10a) these terms are replaced by $1 / \sqrt{C_{\text {io }}}$ due to our assumption of a linear relationship between the ice-ocean shear and the ice-ocean stress velocity.

Our formulation is arguably a less accurate description of the IOBL when the SIC is close to $100 \%$ because it does not allow the ice speed to vary nonlinearly with the ice-ocean stress velocity. However, in general the SIC may be much smaller than $100 \%$, and at any given horizontal location the surface boundary condition is transient, varying between a solid upper boundary (the ice) and a free surface (open water). Thus the assumption of a flow following the law of the wall and the notion of a hydraulic roughness length no longer applies to this case. We have therefore assumed quadratic drag laws at these interfaces for simplicity, but in principle a more accurate IOBL model could be derived following the ideas of Rossby similarity theory but using a transient surface boundary condition that varies between a solid boundary and a free surface.

\subsubsection{Turning angles}

The IOBL turning angle is the angle between the ice-ocean stress velocity $\boldsymbol{u}_{\mathrm{io}}^{*}$ and the ice-geostrophic shear $\left(\boldsymbol{u}_{\mathrm{i}}-\boldsymbol{u}_{\mathrm{g}}\right)$, and may be defined as

$\cos \left(\theta_{\mathrm{IOBL}}\right)=\frac{\boldsymbol{u}_{\mathrm{i}}^{*} \cdot\left(\boldsymbol{u}_{\mathrm{i}}-\boldsymbol{u}_{\mathrm{g}}\right)}{\left|\boldsymbol{u}_{\mathrm{i} \mathrm{i}}^{*}\right|\left|\boldsymbol{u}_{\mathrm{i}}-\boldsymbol{u}_{\mathrm{g}}\right|}$.

For near- $100 \%$ SIC, a closed expression for the IOBL turning angle can be derived by substituting the right-hand side of Eq. (10a) for $\boldsymbol{u}_{\mathrm{i}}-\boldsymbol{u}_{\mathrm{g}}$ in Eq. (19),

$\cos \left(\theta_{\mathrm{IOBL}}\right)=\frac{1+\alpha}{\sqrt{1+(1+\alpha)^{2}}}$,

which is independent of the surface wind speed and depends only on the parameter $\alpha=\sqrt{2 K_{0}^{*} / C_{\mathrm{io}}}$. Thus for near$100 \%$ SIC, prescribing an Ekman spiral and a linear relationship between the ice-ocean stress velocity $\boldsymbol{u}_{\text {io }}^{*}$ and the ice-ocean shear $\left(\boldsymbol{u}_{\mathrm{i}}-\boldsymbol{u}_{\mathrm{o}}\right)$ is equivalent to assuming a constant geostrophic ice-ocean turning angle (e.g., Hibler III, 1979; Thorndike and Colony, 1982). By contrast the IOBL turning angle predicted by Rossby similarity theory varies as a function of the ice-ocean stress velocity, and the turning angle varies by a few degrees over a realistic range of iceocean stress magnitudes (McPhee, 1979, 2008). Note that in our model $\theta_{\mathrm{IOBL}}$ is generally not independent of the surface wind speed when the SIC is below $100 \%$.

Figure 2 shows the IOBL turning angle $\theta_{\text {IOBL }}$ as a function of $\alpha$. The IOBL turning angle $\theta_{\mathrm{IOBL}}$ decreases from 45 degrees to 0 as $\alpha$ increases from 0 to infinity. A larger value of $\alpha$ corresponds to a relatively large vertical diffusivity $K_{0}^{*}$, which tends to reduce the magnitude of the shear in the Ekman layer. Thus the shear becomes dominated by the surface boundary layer, over which the shear does not turn with depth. A smaller value of $\alpha$ corresponds to a relatively large drag coefficient $C_{\text {io }}$, which tends to reduce magnitude of the shear in the surface boundary layer. Thus the shear becomes dominated by the Ekman spiral, over which the shear turns by $45^{\circ}$. This is consistent with Rossby similarity theory (McPhee, 2008, 2012) in that multi-year ice pack with a relatively high basal hydraulic roughness corresponds to a larger 
turning angle $\theta_{\mathrm{IOBL}}$. In this study, we employ the canonical value of $K_{\mathrm{o}}^{*}=0.028$ (McPhee, 1994, 2008), and we use $C_{\mathrm{io}}=0.0071$ based on the estimate of Cole et al. (2014) from the ice-tethered profiler with a velocity sensor (ITP-V) data. This combination of $K_{\mathrm{o}}^{*}$ and $C_{\text {io }}$ produces a $\theta_{\mathrm{IOBL}}$ of around $15^{\circ}$ (red dot in Fig. 2). This value is within the range of turning angles predicted by Rossby similarity theory, which is about $20^{\circ}$ for multi-year ice pack and $13^{\circ}$ for the first-year ice (McPhee, 2012).

We now turn to the ice drift itself. We derive the angle between the $10 \mathrm{~m}$ wind speed $\boldsymbol{u}_{\mathrm{a}}$ and the ice-geostrophic shear $\boldsymbol{u}_{\mathrm{i}}-\boldsymbol{u}_{\mathrm{g}}$ by taking the dot product of $\boldsymbol{u}_{\mathrm{ai}}^{*}$ with Eq. (10a), noting that $\boldsymbol{u}_{\mathrm{ai}}^{*}$ lies parallel to $\boldsymbol{u}_{\mathrm{a}}$ from Eq. (6a), and using Eqs. (14) and (15) for the components of $\boldsymbol{u}_{\mathrm{io}}^{*}$ :

$$
\begin{aligned}
\cos \left(\theta_{\mathrm{ai}}\right) & =\frac{\boldsymbol{u}_{\mathrm{a}} \cdot\left(\boldsymbol{u}_{\mathrm{i}}-\boldsymbol{u}_{\mathrm{g}}\right)}{\left|\boldsymbol{u}_{\mathrm{a}}\right|\left|\boldsymbol{u}_{\mathrm{i}}-\boldsymbol{u}_{\mathrm{g}}\right|}=\frac{k_{\mathrm{o}}\left|\boldsymbol{u}_{\mathrm{io}}^{*}\right|^{2}}{k_{\mathrm{a}}\left|\boldsymbol{u}_{\mathrm{ai}}^{*}\right|^{2}} \frac{1+\alpha}{\sqrt{1+(1+\alpha)^{2}}} \\
& =\frac{\left|\boldsymbol{\tau}_{\mathrm{io}}\right|}{\left|\boldsymbol{\tau}_{\mathrm{ai}}\right|} \cos \left(\theta_{\mathrm{IOBL}}\right) .
\end{aligned}
$$

Using Eq. (16) above, it is straightforward to show that the ratio of the ice-ocean to air-ice stresses is smaller than 1 , $k_{\mathrm{o}}\left|\boldsymbol{u}_{\mathrm{io}}^{*}\right|^{2} / k_{\mathrm{a}}\left|\boldsymbol{u}_{\mathrm{ai}}^{*}\right|^{2}=\left|\boldsymbol{\tau}_{\mathrm{io}}\right| /\left|\boldsymbol{\tau}_{\mathrm{ai}}\right|<1$, so it follows that the airice angle is always at least as large as the IOBL turning angle, $\theta_{\mathrm{ai}} \geq \theta_{\mathrm{IOBL}}$ This reflects the fact that the $10 \mathrm{~m}$ wind velocity $\boldsymbol{u}_{\mathrm{a}}$ always points to the left of the ice-ocean stress $\boldsymbol{\tau}_{\text {io }}$ (cf. Eqs. 14 and 15), while the ice-geostrophic shear $\boldsymbol{u}_{\mathrm{i}}-\boldsymbol{u}_{\mathrm{g}}$ always points to the right of $\boldsymbol{\tau}_{\text {io }}$ (cf. Eq. 10a). For strong winds $\left(\left|\boldsymbol{\tau}_{\text {ai }}\right| \rightarrow \infty\right)$ Eq. (16) implies that the air-ice and iceocean stresses balance one another in Eq. (3) (i.e., $\boldsymbol{\tau}_{\text {io }} \rightarrow \boldsymbol{\tau}_{\text {ai }}$ ), so the air-ice turning angle becomes independent of the wind speed and equal to the IOBL turning angle. For weak winds $\left(\left|\boldsymbol{\tau}_{\mathrm{ai}}\right| \rightarrow 0\right)$, Eq. (16) implies that the ice-ocean to air-ice stress ratio vanishes ${ }^{1},\left|\boldsymbol{\tau}_{\text {io }}\right| /\left|\boldsymbol{\tau}_{\text {ai }}\right| \rightarrow 0$, so from Eq. (18) the ice velocity becomes directed $90^{\circ}$ to the right of the winds.

\section{Observation and reanalysis data sets}

In this section we detail the various observational and reanalysis data sets used to evaluate our analytical model and to quantify how southerly winds affects Arctic summer SIC.

\subsection{Observations}

To evaluate our analytical model with observations, we used observations from an ice-tethered profiler (Toole et al., 2010) equipped with a velocity sensor (Williams et al., 2010). Specifically, we use data from ITP-V 35, which was deployed

\footnotetext{
${ }^{1}$ To obtain this result from Eq. (16), first note that if $\left|\boldsymbol{u}_{\mathrm{ai}}^{*}\right|=0$ then the only non-negative real solution to Eq. (16) is $\left|\boldsymbol{u}_{\text {io }}^{*}\right|=0$, so we can conclude that $\left|\boldsymbol{u}_{\mathrm{io}}^{*}\right| \rightarrow 0$ as $\left|\boldsymbol{u}_{\mathrm{ai}}^{*}\right| \rightarrow 0$. Then note that in the limit of vanishing air-ice stress, $\left|\boldsymbol{u}_{\mathrm{ai}}^{*}\right| \rightarrow 0$, Eq. (16) can only remain balanced if $\left|\boldsymbol{u}_{\text {io }}^{*}\right| \sim\left|\boldsymbol{u}_{\text {ai }}^{*}\right|^{2}$. It follows that $\left|\boldsymbol{\tau}_{\text {io }}\right| /\left|\boldsymbol{\tau}_{\text {ai }}\right| \rightarrow 0$ as $\left|\boldsymbol{u}_{\mathrm{ai}}^{*}\right| \rightarrow 0$.
}

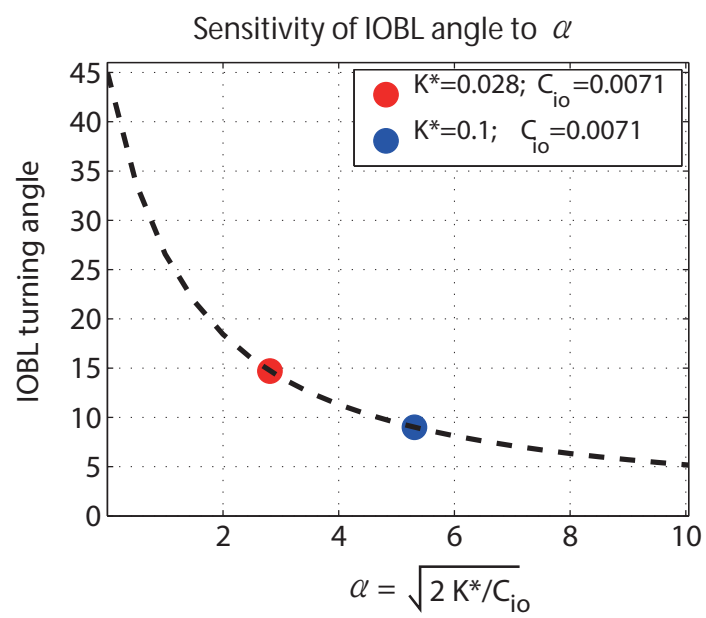

Figure 2. Sensitivity of the IOBL turning angle $\left(\theta_{\mathrm{IOBL}}\right)$ to $\alpha$ $\left(=\sqrt{2 K_{0}^{*} / C_{\text {io }}}\right)$, calculated from Eq. (20), which is for $\varphi \sim 1$. The red dot corresponds to the canonical value for the vertical eddy diffusivity $\left(K_{\mathrm{o}}^{*}=0.028\right)$ and the blue dot corresponds to a nominally increased value $\left(K_{\mathrm{O}}^{*}=0.1\right)$.

on 8 October 2009 on an ice floe in the Beaufort Sea at $77^{\circ} \mathrm{N}, 135^{\circ} \mathrm{W}$, as part of the Beaufort Gyre Observing System (BGOS). The ice floe was $2.6 \mathrm{~m}$ thick, so hydrostatic adjustment resulted in an ice-ocean interface at around $2.3 \mathrm{~m}$ depth (Cole et al., 2014). Ocean velocity profiles were obtained every $4 \mathrm{~h}$ to $150 \mathrm{~m}$ depth, with an effective vertical resolution of $1 \mathrm{~m}$. To examine the ice-ocean shear $\left(\boldsymbol{u}_{\mathrm{i}}-\boldsymbol{u}_{\mathrm{o}}\right)$ and the ice-ocean velocity angle, we use the shallowest measurements from the velocity profiles, at a depth of $7 \mathrm{~m}$. The ice velocity $\left(\boldsymbol{u}_{\mathrm{i}}\right)$ is derived from hourly GPS fixes and linearly interpolated in time to align with the time of the ITPV 35 observations. Further details, including calibrations and a discussion of errors in ITP-V 35, are described by Cole et al. (2014).

Arctic SIC data are from the US National Snow and Ice Data Center (NSIDC) and are based on satellite-derived passive microwave brightness temperature. Specifically, the NASA Team Algorithm (Swift and Cavalieri, 1985) was used to estimate the SIC. These data are provided as a daily mean on a polar stereographic grid with $25 \mathrm{~km} \times 25 \mathrm{~km}$ resolution. We re-gridded these data onto a regular $1.0^{\circ} \times 1.0^{\circ}$ grid.

\subsection{Reanalysis}

Observations of Arctic sea ice thickness are sparse, so instead we use the coupled Pan-arctic Ice-Ocean Modeling and Assimilation System (PIOMAS; Zhang and Rothrock, 2003) to estimate the basin-scale Arctic sea ice thickness. PIOMAS consists of a 12-category thickness and enthalpy distribution sea ice model coupled with the POP (Parallel Ocean Program) ocean model (Smith et al., 1992). The data are monthly and cover the years from 1978 to 2013. For the surface wind stress we used $10 \mathrm{~m}$ winds provided by the European Center 
for Medium-Range Weather Forecasts ERA-Interim reanalysis data set (Dee et al., 2011). The data are 6 hourly with a horizontal resolution of $1.0^{\circ} \times 1.0^{\circ}$.

\section{Model evaluation}

In this section, we evaluate our analytical model against the ITP-V 35 observations of sub-sea ice ocean velocity (Cole et al., 2014). Specifically, we compare the modeled wind-ice and ice-ocean velocity angles against the observed values. As outlined in the introduction, one might not expect the winter Beaufort Sea to serve as a useful test case because the SIC is typically close to $100 \%$, so the internal stresses neglected in our model may be dynamically significant (Leppäranta, 2005). Additionally, sea ice formation in winter may produce negative buoyancy forcing that induces strong convection and vertically varying eddy viscosity in the surface mixed layer, inconsistent with our assumption of as uniform vertical viscosity throughout the Ekman layer (McPhee, 2012). However, the ITP-V 35 measurements indicate that the ice was very close to a free drift regime and experienced weak vertical buoyancy fluxes in the surface mixed layer (Cole et al., 2014), so these features of the winter sea ice pack may be less prominent than in previous observations. For a complete picture of the stratification regime in the observed nearsurface ocean, see Figs. 3, 4, 8, and 9 of Cole et al. (2014). For example, the mixed layer depth over the Beaufort Sea is very shallow in October $(\sim 15 \mathrm{~m})$ and deepens to $30-40 \mathrm{~m}$ in February and March (Fig. 9 of Cole et al., 2014).

\subsection{Model parameters}

The ITP-V 35 was deployed upon a $2.6 \mathrm{~m}$ thick ice floe, which is much thicker than the mean ice thickness over the western Beaufort Sea. Figure 1a shows the PIOMAS sea ice thickness averaged from October 2009 to March 2010. During this time period, sea ice thickness over the western Beaufort Sea (around $74-78^{\circ} \mathrm{N}, 135-150^{\circ} \mathrm{W}$ ) is around 1.4$1.6 \mathrm{~m}$. It is therefore likely that ITP-V 35 was mounted on a relatively sturdy floe, whereas the surrounding floes were thinner. SIC over this region is mostly over $85-90 \%$ from October to March (Fig. 1b). We use $\varphi=1$ as a reference case because, as we will show below, the ice drift speed and angle predicted by our model are insensitive to $\varphi$ for SICs greater than $\sim 50 \%$. The velocity of the mixture layer (see Sect. 2) represents a bulk average over many floes, and similarly the ocean Ekman layer in any given location responds to stresses transmitted by a series of ice floes passing overhead. For the purpose of model evaluation we therefore take the sea ice thickness $h_{\mathrm{i}}$ to be $1.5 \mathrm{~m}$, which is appropriate for basin-scale sea ice momentum balance, rather than a momentum balance at the scale of the individual ice floe.

Extensive measurements of the ice-ocean boundary layer suggest that the annual mean value of the dimensionless vertical eddy diffusivity $K_{\mathrm{o}}^{*}$ is about 0.028 (McPhee, 1994, 2008). Below we also present model predictions using a nominal enhanced value of $K_{\mathrm{o}}^{*}=0.1$, which yields improved agreement between the model and the observations. A possible explanation for this is that the ITP-V observations mostly cover winter season (from October to March), when surface buoyancy loss due to sea ice formation can enhance the vertical eddy diffusivity by a factor of up to 10 (McPhee and Morison, 2001). However, it is more likely that internal stresses in the ice impede its motion, so the canonical value of $K_{\mathrm{o}}^{*}=0.028$ overestimates the ice drift. Thus the reader should not infer from our results that using a larger value of $K_{\mathrm{o}}^{*}$ is more physically realistic. Finally, the geostrophic current in the interior of polar oceans, $\boldsymbol{u}_{\mathrm{g}}$, is poorly constrained, and we assume that this term is small relative to the surface current. This assumption should be more robust on intraseasonal timescales, as surface winds can strengthen rapidly in a few days, so the resultant surface Ekman velocity is likely to be much larger than the interior geostrophic flow.

For other parameters, we used standard values used in many previous studies: $\rho_{\mathrm{a}}=1.35 \mathrm{Kg} \mathrm{m}^{-3}, \rho_{\mathrm{i}}=910 \mathrm{Kg} \mathrm{m}^{-3}$, and $\rho_{\mathrm{o}}=1026 \mathrm{Kg} \mathrm{m}^{-3}$. The atmospheric drag coefficients $C_{\mathrm{ai}}$ and $C_{\mathrm{ao}}$ depend on the season, the ice fraction, and the surface roughness (Lüpkes et al., 2012), but for simplicity we use constant values of $C_{\mathrm{ai}}=1.89 \times 10^{-3}$ and $C_{\mathrm{ao}}=1.25 \times 10^{-3}$ (Lüpkes and Birnbaum, 2005). We prescribe the ice-ocean drag coefficient $C_{\text {io }}$ based on the findings of Cole et al. 2014), who found that $C_{\mathrm{io}}=7.1 \times 10^{-3}$ best fit the ITP-V 35 measurements. However, we note that it is difficult to calculate $C_{\mathrm{io}}$ accurately from the ITP-V data because measurements of the vertical eddy momentum fluxes were made at a depth of $6 \mathrm{~m}$. This depth lies partway into the Ekman layer, so we expect the stress to be rotated and reduced in magnitude relative to the stress at the ice base.

\subsection{Results}

Figure 3 shows the observed ice speed (black line) as a function of the $10 \mathrm{~m}$ wind speed. Consistent with Thorndike and Colony (1982), the relationship is approximately linear, except for weak winds (speed less than $2 \mathrm{~m} \mathrm{~s}^{-1}$ ). For moderately strong winds, sea ice moves with a speed around $1.5-2 \%$ of the surface wind speed. This is consistent with or slightly weaker than the well-known $2 \%$ relationship (Thorndike and Colony, 1982). Figure 3a shows that the analytical model with the canonical value of $K_{\mathrm{o}}^{*}\left(K_{\mathrm{o}}^{*}=0.028\right)$ overestimates the observed ice speed by $20-40 \%$, whereas a larger vertical diffusivity (blue-dotted line; $K_{\mathrm{o}}^{*}=0.1$ ) fits better with the observations. As stated above, this is probably because the internal stresses in the relatively concentrated sea ice (85-100\% in winter) impede the ice drift. We also compare the observed ice drift speeds with those predicted by "classical" free drift (Leppäranta, 2005), in which we neglect both the Ekman layer velocity and the geostrophic velocity. Mathematically this corresponds to assuming an infinitely 


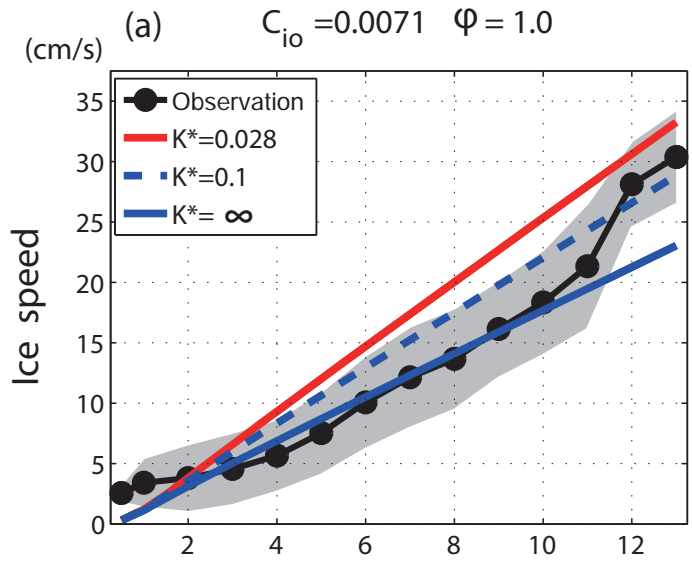

(b) $\quad K^{*}=0.028 \quad C_{i o}=0.0071$
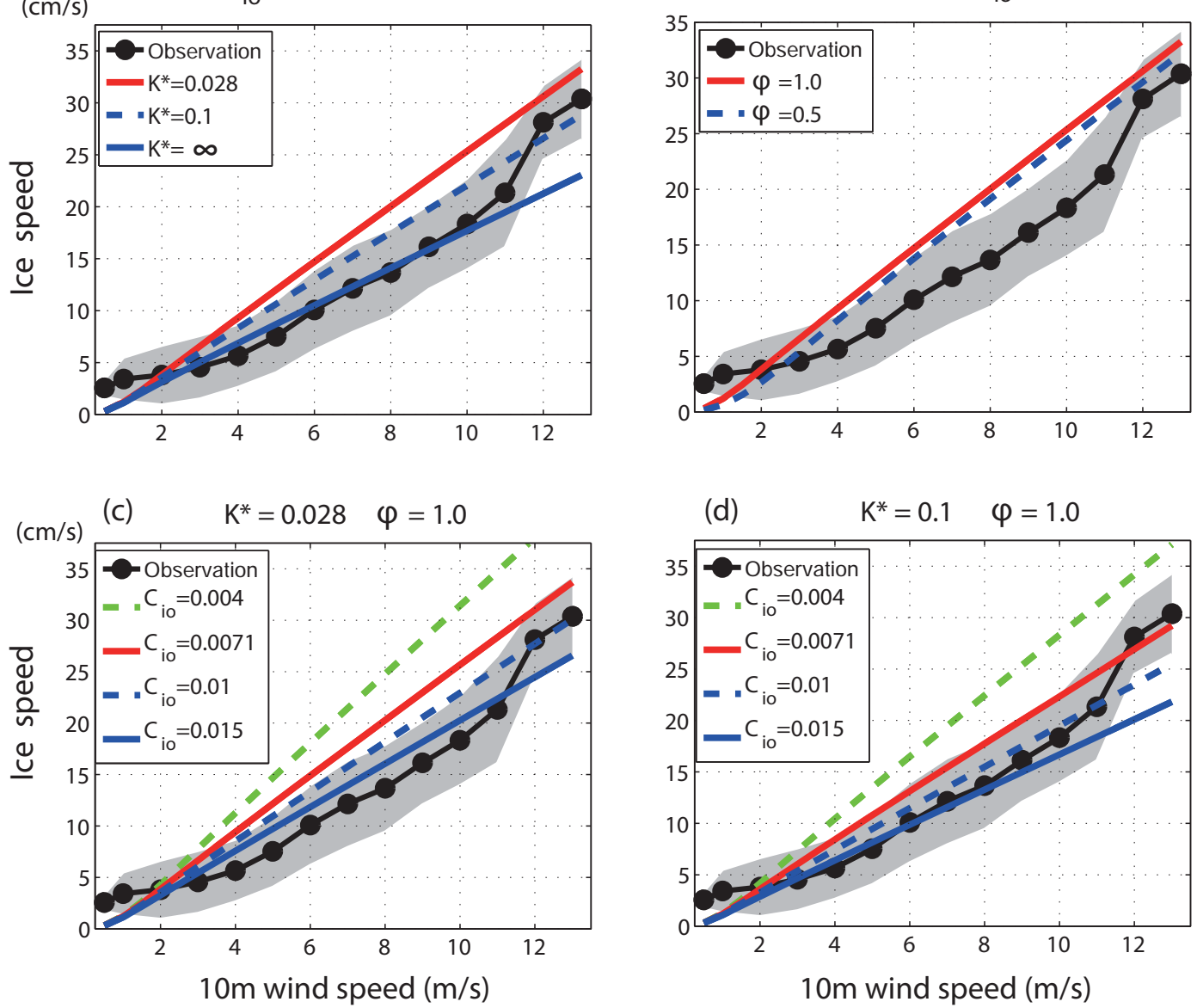

Figure 3. Sensitivity of ice speed $\left(\mathrm{cm} \mathrm{s}^{-1}\right)$ to $10 \mathrm{~m}$ wind speed $\left(\mathrm{m} \mathrm{s}^{-1}\right)$. The black line shows the mean value calculated from ITP-V 35 observations binned by $10 \mathrm{~m}$ wind speed, and the gray shadings indicate the range of 1 standard deviation from the mean. The red, dotted blue, and solid blue lines correspond to our analytical model, described in Sect. 2, with (a) vertical diffusivities $K_{\mathrm{o}}^{*}=0.028,0.1$, and $\infty$ (no IOBL), respectively. The sensitivity of the ice speed to the ice concentration $(\varphi)$ is shown in (b); the red and blue lines indicate $100 \%$ ice cover $(\varphi=1)$ and $50 \%$ ice cover $(\varphi=0.5)$, respectively. The bottom panel shows the sensitivity of ice speed to ice-ocean drag coefficient $\left(C_{\text {io }}\right)$, with vertical diffusivities (c) $K_{\mathrm{O}}^{*}=0.028$ and (d) $K_{\mathrm{O}}^{*}=0.1$, respectively. The bulk sea ice thickness is taken to be $1.5 \mathrm{~m}$.

large vertical diffusivity $\left(K_{\mathrm{o}}^{*} \rightarrow \infty\right)$ in our model. This classical free drift (blue solid line in Fig. 3a) is about $30 \%$ slower than the ice drift with an interactive Ekman layer (red line in Fig. 3a), verifying that the IOBL substantially increases the wind-induced ice speed.

Figure $3 \mathrm{~b}$ shows that there is little difference in ice speed between $100 \%$ sea ice cover (red line; $\varphi=1$ ) and $50 \%$ sea ice cover (red line; $\varphi=1$ ) in this model (Fig. 3b). As shown in Eq. (10a), the ice-ocean drag coefficient, $C_{\text {io }}$, also directly influences the wind-induced ice velocity. The bottom panels of Fig. 3 show the sensitivity of the ice speed to $C_{\text {io }}$ for $K_{\mathrm{o}}^{*}=0.028$ (Fig. 3c) and $K_{\mathrm{o}}^{*}=0.1$ (Fig. 3d), respectively. Decreasing $C_{\mathrm{io}}$ from 0.0071 to 0.004 increases ice speed by up to $20-25 \%$. In the Appendix we calculate $C_{\text {io }}$ using the ITP-V data and plot $C_{\text {io }}$ both as a function of $10 \mathrm{~m}$ wind speed and surface stress (Fig. A1). Consistent with Cole et al. (2014), the individual observed values of $C_{\text {io }}$ vary widely, by a factor of 10. In general, there is no obvious dependence of $C_{\text {io }}$ on the surface stress, so we use the constant value $C_{\text {io }}=0.0071$ of Cole et al. (2014).

Figure 4 shows that the wind-ice velocity angle $\theta_{\text {ai }}$ decreases as the surface wind strengthens, consistent with previous observations (Thorndike and Colony, 1982). The velocity angle is overestimated by $5-10^{\circ}$ in the case when the canonical vertical diffusivity $K_{\mathrm{o}}^{*}=0.028$ is used (Fig. 4a). The analytical model with $K_{\mathrm{o}}^{*}=0.1$ reproduces this curve remarkably well. Recall from Eq. (21) that wind-ice velocity angle $\theta_{\text {ai }}$ decreases as the ice-ocean to wind-ice stress ratio $\left(\left|\boldsymbol{\tau}_{\text {io }}\right| /\left|\boldsymbol{\tau}_{\text {ai }}\right|\right)$ increases and that this stress ratio is always smaller than 1 . Thus, the decrease of $\theta_{\text {ai }}$ with increasing surface wind speed indicates that the stress ratio increases as the surface winds strengthen. In other words, the momentum becomes more efficiently transferred down to the ocean as the surface wind speed increases. For relatively weak winds, 


\section{Wind - ice velocity angle}

(a) Sensitivity to $\mathrm{K}^{*}$

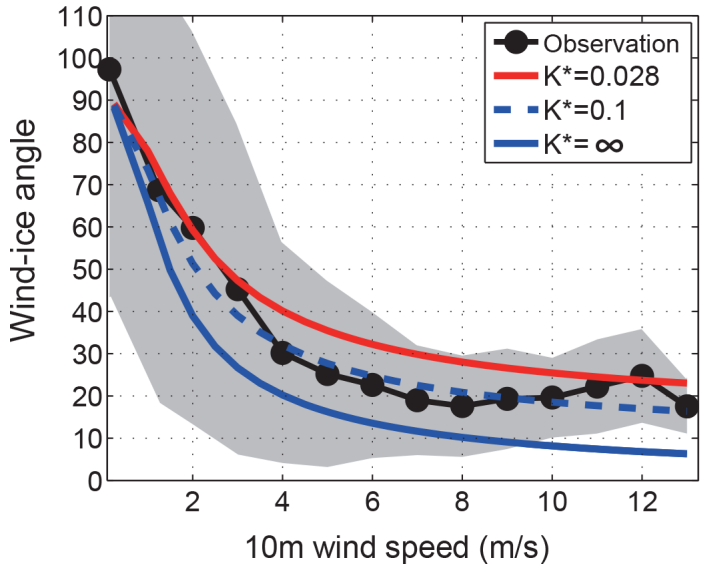

(b) Sensitivity to ice concentration $\varphi$

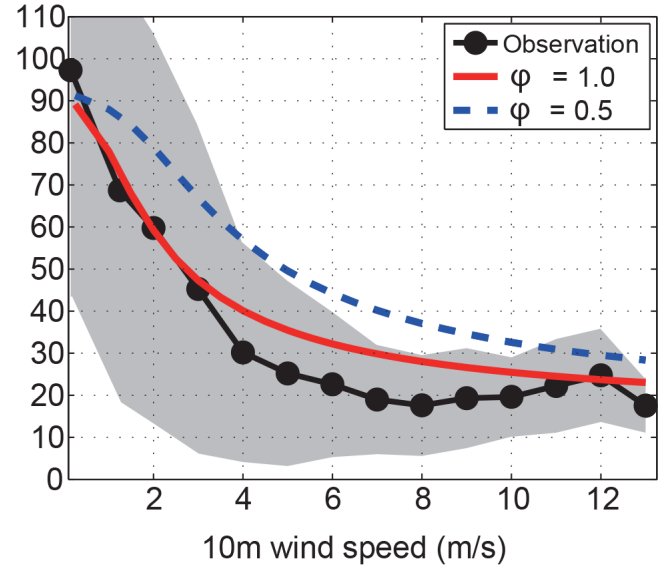

Figure 4. The velocity angle (clockwise rotation angle) between the $10 \mathrm{~m}$ winds and the ITP-V 35 ice floe as functions of the $10 \mathrm{~m}$ wind speed $\left(\mathrm{m} \mathrm{s}^{-1}\right)$. Note that typically the ice velocity lies to the right of the wind velocity. In each plot the black line is the mean observed value from the ITP-V 35 data set, binned by wind speed, and the gray shadings indicate the range of 1 standard deviation from the mean. In (a), the red, dotted blue, and solid blue lines correspond to our analytical model, described in Sect. 2 , with vertical diffusivities $K_{\mathrm{O}}^{*}=0.028,0.1$, and $\infty$ (no IOBL), respectively. In (b), the red and blue lines correspond to $100 \%(\varphi=1)$ and $50 \%(\varphi=0.5)$ sea ice concentrations, in each case using the canonical vertical diffusivity $K_{\mathrm{O}}^{*}=0.028$.

the observational errors in $\theta_{\text {ai }}$ (gray shadings in Fig. 4) are large, whereas for stronger winds the air-ice velocity angle is much better constrained (Cole et al., 2014). The wind-ice velocity angle $\theta_{\text {ai }}$ estimated using the "classical" free drift case is about $20^{\circ}$ smaller than that predicted by the canonical vertical diffusivity $K_{\mathrm{o}}^{*}=0.028$. Moreover, the classical free drift approximation substantially underestimates the observed $\theta_{\text {ai }}$ even though the internal friction is neglected. This result indicates that the IOBL is essential for properly simulating the direction of the ice drift. Figure $4 \mathrm{~b}$ shows that sea ice cover plays a nontrivial role in changing the wind-ice velocity angle $\theta_{\text {ai }}$, although the internal stresses are neglected in the model. Decreasing sea ice cover from $100 \%(\varphi=1)$ to $50 \%(\varphi=0.5)$ increases $\theta_{\mathrm{ai}}$ by $20^{\circ}$ for high wind speeds.

The shallowest measurement depth of ITP-V 35 is $7 \mathrm{~m}$, which is far below the ice base $(\sim 2.6 \mathrm{~m})$. The Ekman spiral rotates the velocity and stress vectors substantially between the ice base and $7 \mathrm{~m}$. Consequently the ITP-V data cannot accurately quantify the IOBL turning angle, which also requires an estimate of the near-surface geostrophic velocity to be made. Instead we test our analytical treatment of the IOBL using the velocity angle between the ice floe and the ocean at $7 \mathrm{~m}:\left.\theta_{\text {io }}\right|_{z=-7 \mathrm{~m}}$. To calculate $\left.\theta_{\text {io }}\right|_{z=-7 \mathrm{~m}}$ from the analytical model, the velocity angle needs to be adjusted using the Ekman layer solution, which can be written as a function depth, $z$, as

$\boldsymbol{u}(z)=\boldsymbol{u}_{\mathrm{o}} \exp \left(\frac{z+h_{\mathrm{o}}}{\delta_{\mathrm{E}}}\right) \exp \left(i \frac{z+h_{\mathrm{o}}}{\delta_{\mathrm{E}}}\right)$.
Here $\boldsymbol{u}_{\mathrm{o}}$ is the ocean surface velocity at the bottom of sea ice, $h_{\mathrm{o}}=\left(\rho_{\mathrm{i}} / \rho_{\mathrm{O}}\right) h_{\mathrm{i}}$ is the depth of the ice base, and $\delta_{\mathrm{E}}=\sqrt{2 K} / f$ is the Ekman depth. We have used complex variables to describe two-dimensional vectors, e.g., $\boldsymbol{u}_{\mathrm{o}}=\left(u_{\mathrm{o}}, v_{\mathrm{o}}\right) \equiv u_{\mathrm{o}}+i v_{\mathrm{o}}$, because this presents changes in vector orientation more intuitively. The complex term, $\exp \left(i\left(z+h_{\mathrm{o}}\right) / \delta_{\mathrm{E}}\right)$, produces a velocity $\left.u\right|_{z=-d}$ at any depth $d$ that is rotated relative to $\boldsymbol{u}_{\mathrm{o}}$ by a clockwise angle of $\left(d-h_{\mathrm{o}}\right) / \delta_{\mathrm{E}}$ radians. Thus the adjusted velocity angle between the ice and the ocean at any depth in the Ekman layer is

$\left.\theta_{\mathrm{io}}\right|_{z=-d}=\left.\theta_{\mathrm{io}}\right|_{z=-h_{\mathrm{o}}}+\left(d-h_{\mathrm{o}}\right) / \delta_{\mathrm{E}}$

In Fig. 5 we plot $\left.\theta_{\text {io }}\right|_{z=-7 \mathrm{~m}}$ as a function of the ice speed, comparing the predictions of our model with the data from Cole et al. (2014). In general, the ice-ocean velocity angle $\left.\theta_{\text {io }}\right|_{z=-7 \mathrm{~m}}$ decreases as ice speed increases. Consistent with Cole et al. (2014), the variance in the observationally derived values of $\left.\theta_{\text {io }}\right|_{z=-7 \mathrm{~m}}$ is quite large, especially for low ice speeds. Our analytical solution for the ice-ocean velocity angle, adjusted using Eq. (23), agrees reasonably well with the ITP-V 35 measurements. Again, the analytical model predicts the observational curve better when the higher vertical diffusivity of $K_{\mathrm{o}}^{*}=0.1$ is used. Figure $5 \mathrm{~b}$ shows that ice concentration is certainly a factor affecting the ice-ocean velocity angle, $\theta_{\mathrm{io}}$. Decreasing sea ice cover from 100 to $50 \%$ causes a decrease in $\theta_{\text {io }}$ because the direction of ice drift is constrained by the wind stress over open water between the ice floes $\left(\boldsymbol{\tau}_{\mathrm{ao}}\right)$ and the associated surface Ekman transport. 
Ice - Ocean velocity angle

(a) Sensitivity to $\mathrm{K}^{*}$

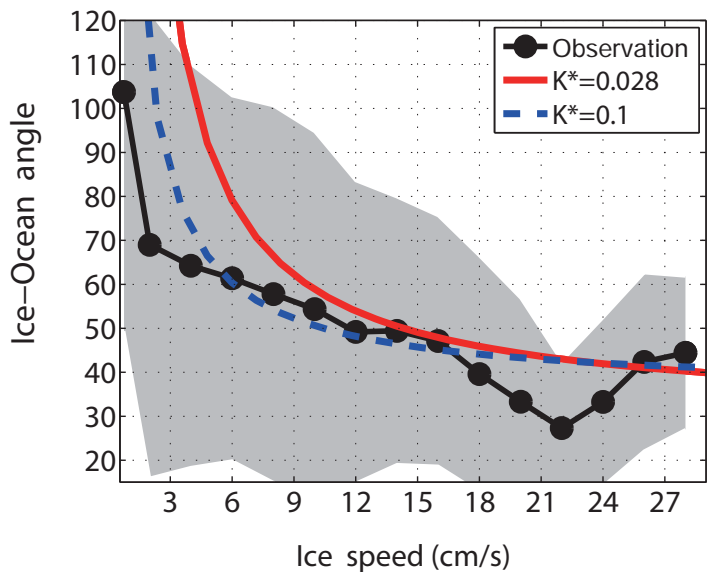

(b) Sensitivity to ice concentration $\varphi$

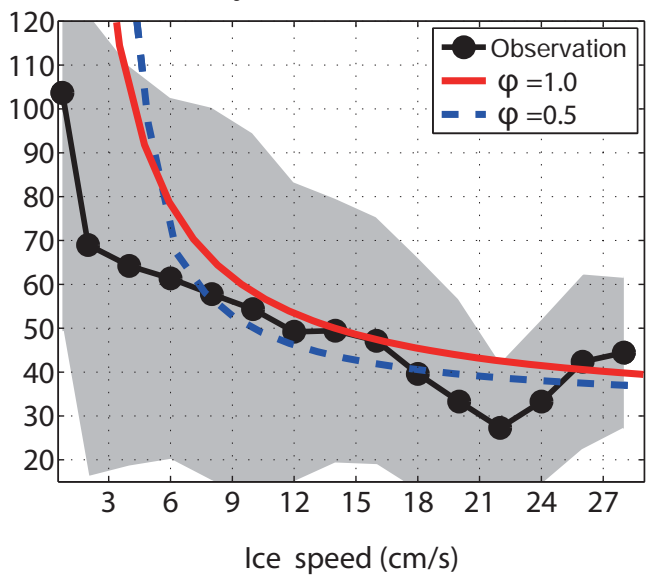

Figure 5. The velocity angle (clockwise rotation angle) between the ice floe and the ocean velocity at $7 \mathrm{~m}$ depth, as functions of the ice speed $\left(\mathrm{cm} \mathrm{s}^{-1}\right)$. In each plot the black line is the mean observed value from the ITP-V 35 data set, binned by ice speed, and the gray shadings indicate the range of 1 standard deviation from the mean. In (a), the red and blue lines correspond to our analytical model, described in Sect. 2, with vertical diffusivities $K_{\mathrm{o}}^{*}=0.028$ and 0.1 , respectively, and using $100 \%$ ice concentration, $\varphi=1$. In (b), the red and blue lines correspond to $100 \%(\varphi=1)$ and $50 \%(\varphi=0.5)$ sea ice concentrations, in each case using the canonical vertical diffusivity $K_{\mathrm{O}}^{*}=0.028$.

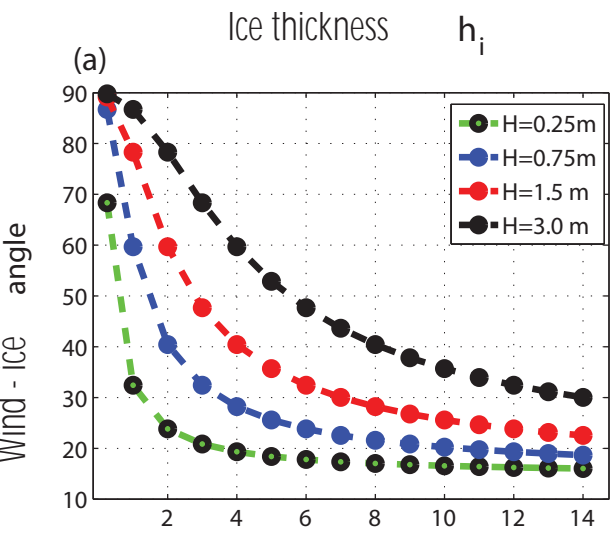

(b)
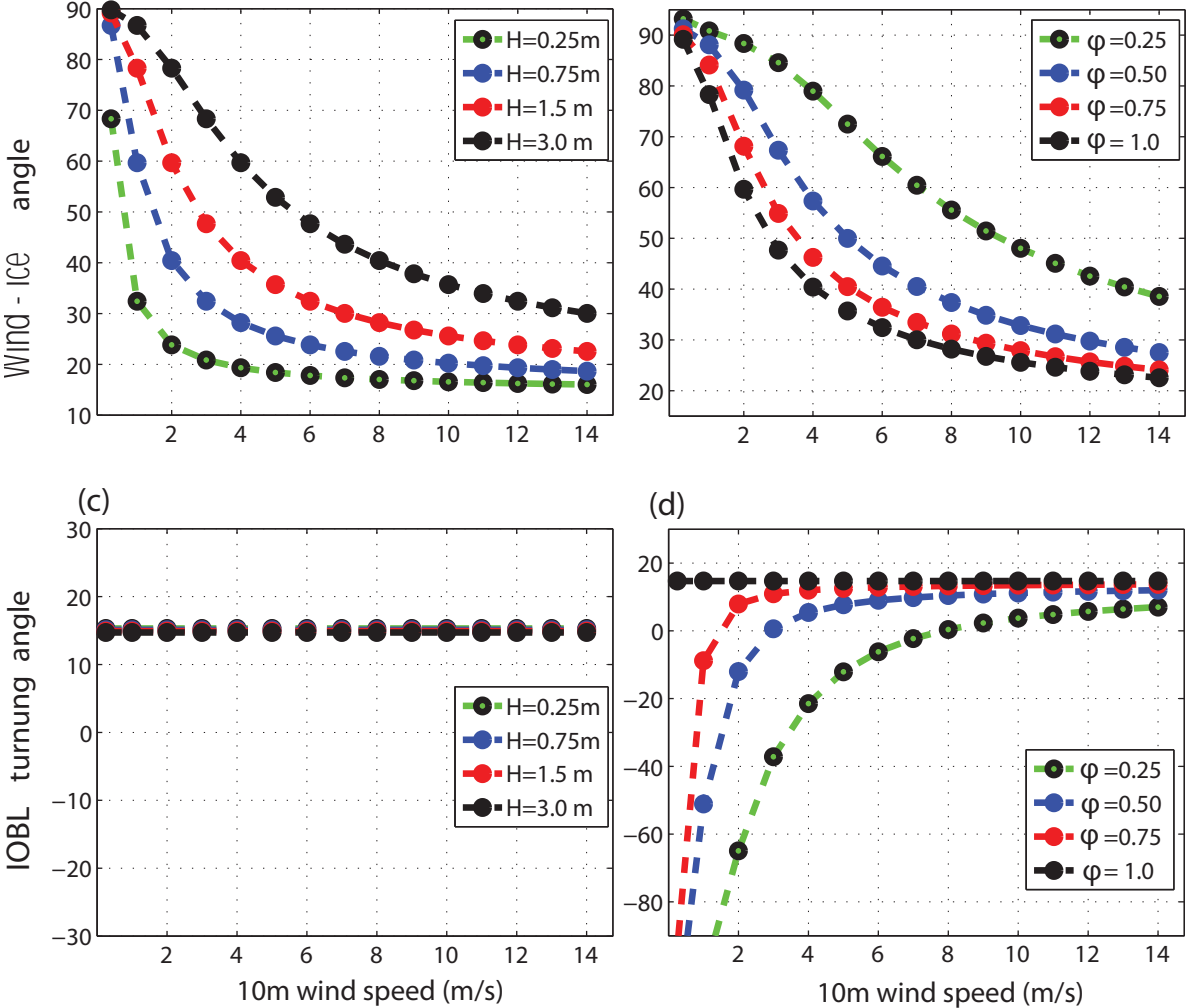

(d)

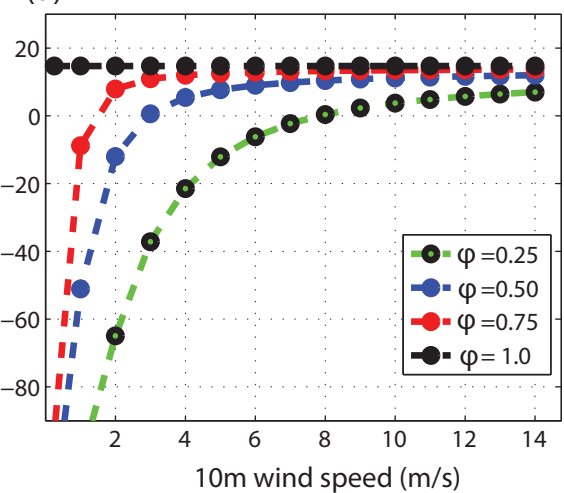

Figure 6. Sensitivity of (a, b) the wind-ice velocity angle and (c, d) the IOBL turning angle to various values of $(\mathbf{a}, \mathbf{c})$ sea ice thickness $h_{\mathrm{i}}$ $(\mathrm{m})$ and $(\mathbf{b}, \mathbf{d})$ sea ice concentration $(\varphi)$ as a function of $10 \mathrm{~m}$ wind speed (abscissa; $\mathrm{m} \mathrm{s}^{-1}$ ). In all panels the dimensionless vertical diffusivity is fixed at $K_{\mathrm{o}}^{*}=0.028$. In (a, c) we use $100 \%$ sea ice concentration $(\varphi=1)$, and in $(\mathbf{b}, \mathbf{d})$ we use a sea ice thickness of $h_{\mathrm{i}}=1.5 \mathrm{~m}$. 


\subsection{Parameter sensitivity}

Having evaluated our model against the ITP-V 35 measurements using the best available estimates for the model parameters, we now explore the sensitivity of the model's predictions to key physical properties of the sea ice itself, namely its thickness and concentration. In Fig. 6 we plot the sensitivity of the wind-ice velocity angle $\left(\theta_{\mathrm{ai}}\right)$ and the IOBL turning angle $\left(\theta_{\mathrm{IOBL}}\right)$ to a range of SICs $(\varphi)$ and ice thicknesses $\left(h_{\mathrm{i}}\right)$. In general, the wind-ice velocity angle increases substantially with sea ice thickness (Fig. 6a): for a moderate wind speed of $6 \mathrm{~m} \mathrm{~s}^{-1}$, increasing the sea ice thickness from 0.25 to $3 \mathrm{~m}$ increases this angle from 20 to $50^{\circ}$. It can therefore be inferred from Eq. (21) and Fig. 6a that thicker ice has smaller stress ratio $\left|\boldsymbol{\tau}_{\text {io }}\right| /\left|\boldsymbol{\tau}_{\text {ai }}\right|$, implying that thicker ice is less efficient in transferring the momentum into the ocean, leading to larger wind-ice velocity angle. In other words, thicker ice absorbs more of the wind-input momentum into the Coriolis torque, transmitting less to the ocean below.

SIC also strongly influences these angles. Consistent with Fig. 4b, Fig. 6b shows that wind-ice velocity angle increases as SIC decreases. There is little difference in this angle between 100 and $75 \%$ ice concentrations - the angle is less sensitive to relatively high SIC. However, the angle rapidly increases as SIC gets below 50\%: at 25\% SIC the wind-ice angle is $20^{\circ}$ larger than at $100 \%$ concentration, even for the strongest winds in the data set. The response of the IOBL turning angle to the mixture of sea ice and water $(\varphi \ll 1)$ is presented in Fig. 6d. The turning angle is negative for weaker surface winds in the case when SIC is less than $100 \%$. This is because wind stress over the ice-free component of the mixture layer is transmitted directly to the water below. As the SIC approaches 0, the stress transmitted through the ice becomes negligible in determining the direction of the surface Ekman velocity $\left(\boldsymbol{u}_{\mathrm{o}}\right)$. Because the ITP-V 35 track covers mostly ice-covered regions $(\varphi \approx 1)$ and the shallowest measurement depth is $7 \mathrm{~m}$, it is difficult to verify whether negative IOBL turning angles appear in the observations.

\section{Application to wind-driven summer sea ice changes}

In this section, we quantify the effect of intra-seasonal southerly wind strengthening events on Arctic sea ice cover using near-surface wind data and compare the results with satellite observations. There are several notable Arctic weather perturbations in the spring and summer over the Pacific sector of the Arctic Ocean, such as the development of the Arctic dipole mode (Wu et al., 2006), quasi-stationary cyclonic winds (Serreze et al., 2003), and synoptic cyclones (Zhang et al., 2013). These perturbations are often accompanied by rapid strengthening of southerlies and a reduction of the SIC on intraseasonal timescales. In the Arctic summer, sea ice thickness is mostly below $2 \mathrm{~m}$ (Fig. 7a) and the area of the marginal ice zone with a moderate SIC $(25-75 \%)$ is quite large (Fig. 7b). We therefore hypothesize that the strengthening of southerlies should efficiently redistribute the sea ice cover in the summer.

This analysis simultaneously serves as an additional evaluation of our analytical model described in Sect. 2. Our model is particularly appropriate to motions in the marginal ice zone, where internal stresses are negligible, and to shortduration intensification of the southerly winds, during which the surface ocean velocity is typically large compared to the geostrophic velocity. This evaluation could in principle be extended to compare the modeled sea ice velocities directly against sea ice drift products. However, we have chosen to retain our focus on the SIC rather than the ice drift velocity. Ice drift products exhibit considerable uncertainty, particularly during summer when the ice is typically thinner (Sumata et al., 2014). Furthermore, there is considerable variance in the ice speed and the wind-ice velocity angle even in the ITP-V data (see Figs. 3 and 4), in which the ice velocities are measured accurately using GPS fixes.

\subsection{Methods}

For surface wind forcing, we used the ERA-Interim reanalysis. Arctic SIC data are from the NSIDC. The Arctic SIC shows multi-decadal declining trend and this trend was removed for each calendar day and for each grid. For sea ice thickness, we used the climatological mean PIOMAS sea ice thickness data averaged from 1990 to 2012.

Using the analytical solutions derived in Sect. 2, sea ice velocity is calculated from the ERA-Interim daily $10 \mathrm{~m}$ winds. Then, lagged composite analyses are performed in order to investigate how a rapid development of southerlies affects SIC during the Arctic summer. We used data from 1990 to 2012 and focused on the summer, from 1 August to 30 September (AS). To define the events of the rapid strengthening of southerlies, the surface winds over the $\mathrm{Pa}$ cific sector of the Arctic are zonally and meridionally averaged, from 150 to $230^{\circ} \mathrm{E}$ and from 70 to $90^{\circ} \mathrm{N}$ (cosine weighting is applied to each latitude). Then, the southerly wind event is defined as a time period when the averaged southerly wind value exceeds 1 standard deviation for 3 or more consecutive days. If the beginning of an event occurs within 7 days of the end of the preceding event, then the latter event is discarded. This procedure identifies 27 events during the analysis period. Lag zero is defined as the day when the averaged southerly winds peak. Prior to generating the composites, a 3-day moving average is applied to filter out noise associated with day-to-day fluctuations.

The southerly wind-induced sea ice drifts redistribute SIC. This effect is computed using the following evolution equation: $\mathrm{d} \varphi=-\left[\frac{\partial\left(U_{\mathrm{i}} \varphi\right)}{\partial x}+\frac{\partial\left(V_{\mathrm{i}} \varphi\right)}{\partial y}\right] \mathrm{d} t$. Here $\varphi$ SIC, which ranges from 0 to 1 , at each grid point, and $\mathrm{d} t$ is a time step, which has a length of 1 day in this study. To calculate SIC anomalies we subtract the long-term climatological mean $d \varphi$ from the daily $d \varphi$ during the southerly wind events. Then, the anoma- 


\section{(a) Sea-ice thickness (Aug-Sep)}

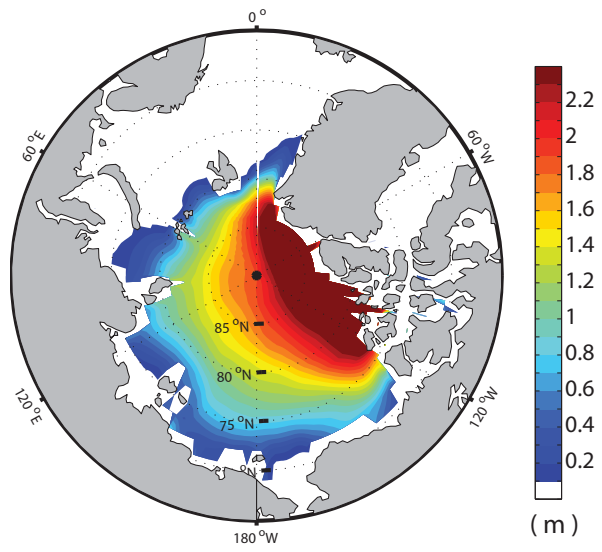

(b) Sea-ice concentration (Aug-Sep)

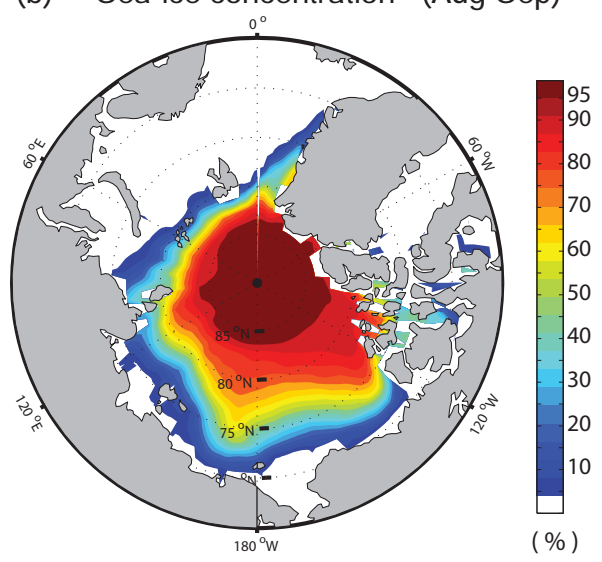

Figure 7. August-September climatological mean (a) sea ice thickness (m) and (b) sea ice concentration (\%) between 1990 and 2012. Sea ice thickness is from PIOMAS and sea ice concentration data are from NSDIC.

lous daily $d \varphi$ is integrated from the lag day -8 to estimate the cumulative changes in SIC associated with the southerly wind events:

$\Delta \varphi=-\sum_{t=-8}^{t=\operatorname{lag}}(d \varphi)^{\prime} \mathrm{d} t=-\sum_{t=-8}^{t=\operatorname{lag}}\left[\frac{\partial\left(U_{\mathrm{i}} \varphi\right)}{\partial x}+\frac{\partial\left(V_{\mathrm{i}} \varphi\right)}{\partial y}\right]^{\prime} \mathrm{d} t$.

Here, prime ()$^{\prime}$ denotes a deviation from the long-term climatological mean. The time integration starts from the lag day -8 because the southerly wind events, on average, start about a week before they peak. The results we present are not very sensitive to the starting date. The maximum and the minimum values of the cumulative changes in $\operatorname{SIC}(\Delta \varphi)$ are limited by the mean SIC, which ranges between 0 and $100 \%$. For example, if the cumulative changes in the mean SIC $(\Delta \varphi+\bar{\varphi})$, where $\bar{\varphi}$ is the climatological-mean SIC, exceed $100 \%$, then $\Delta \varphi$ is given as $(100-\bar{\varphi}) \%$. All of the analytical model results presented here use the canonical value of vertical diffusivity $\left(K_{\mathrm{o}}^{*}=0.028\right)$ and the ice-ocean drag coefficient of $C_{\mathrm{io}}=0.0071$ (Cole et al., 2014). As shown in Fig. 3, the wind-induced ice speed is sensitive to both $K_{\mathrm{o}}^{*}$ and $C_{\text {io. }}$.

\subsection{Results}

Figure 8 illustrates the response of the SIC (shadings in the left column) to the development of southerlies (vectors in the left column) from the East Siberian and Chukchi Sea. Over a 10-day period since the development of southerlies, the SIC in these regions decreases by $7-8 \%$. We suggest that the reduction of SIC is caused by the southerly windinduced sea ice drift. In the meantime, because of crosspolar flow, SIC on the Atlantic sector slightly increases (blue color). To further test this possibility, the wind-induced redistribution of SIC is calculated using our model, specifically Eqs. (17)-(18). The result, shown in the right column of Fig. 8, captures the spatial pattern in the observed SIC anomalies. The anomalous sea ice velocity (vectors in the right column) is generally directed towards the Beaufort Sea, a little east of the surface wind velocity with the drift angle ranging between 20 and $45^{\circ}$. The calculated SIC anomalies at day +6 (bottom row of Fig. 8) are largely consistent with the satellite-observed SIC anomalies. However, the calculated SIC anomalies somewhat underestimate the observation. At day +6 , the calculated reduction of SIC over the Pacific sector is about $5-6 \%$, whereas the observed reduction of SIC is up to 6-8\%. The increase in SIC over the Atlantic sector associated with cross-polar flow is also slightly underestimated.

There are several possible explanations for the discrepancy between the modeled and observed SIC anomalies. Over the Atlantic sector, the cross-polar flow increases SIC and the internal stresses are likely to increase as well. As mentioned earlier, our analytical model neglects internal stresses that can decelerate ice drift and pile up sea ice over the Atlantic sector. It is possible that the real sea ice thickness in the Arctic summer is thinner than the PIOMAS sea ice thickness. While PIOMAS simulates the Arctic sea ice thickness within a reasonable range, the model is known to generally overestimate the thickness of measured sea ice thinner than $2 \mathrm{~m}$ (Johnson et al., 2012; Schweiger et al., 2011). Otherwise, the vertical diffusivity $K_{0}^{*}$ in August and September might be smaller than 0.028 due to surface buoyancy input resulting from sea ice melt (McPhee and Morison, 2001). The formation of a summer freshwater layer at the ice base can also reduce the ice-ocean drag coefficient $C_{\text {io }}$ (Randelhoff et al., 2014) by changing the shape of the ice base. Additionally, the atmosphere-ice drag coefficient may be larger during the summer season due to additional form stress associated with the formation of leads and melt ponds (Lüpkes et al., 2012).

Finally, we ask to what extent the IOBL accelerates the wind-induced ice drift. We have neglected the ocean surface geostrophic velocity in our analytical model calculations, retaining only the surface Ekman layer. However, if the Ek- 

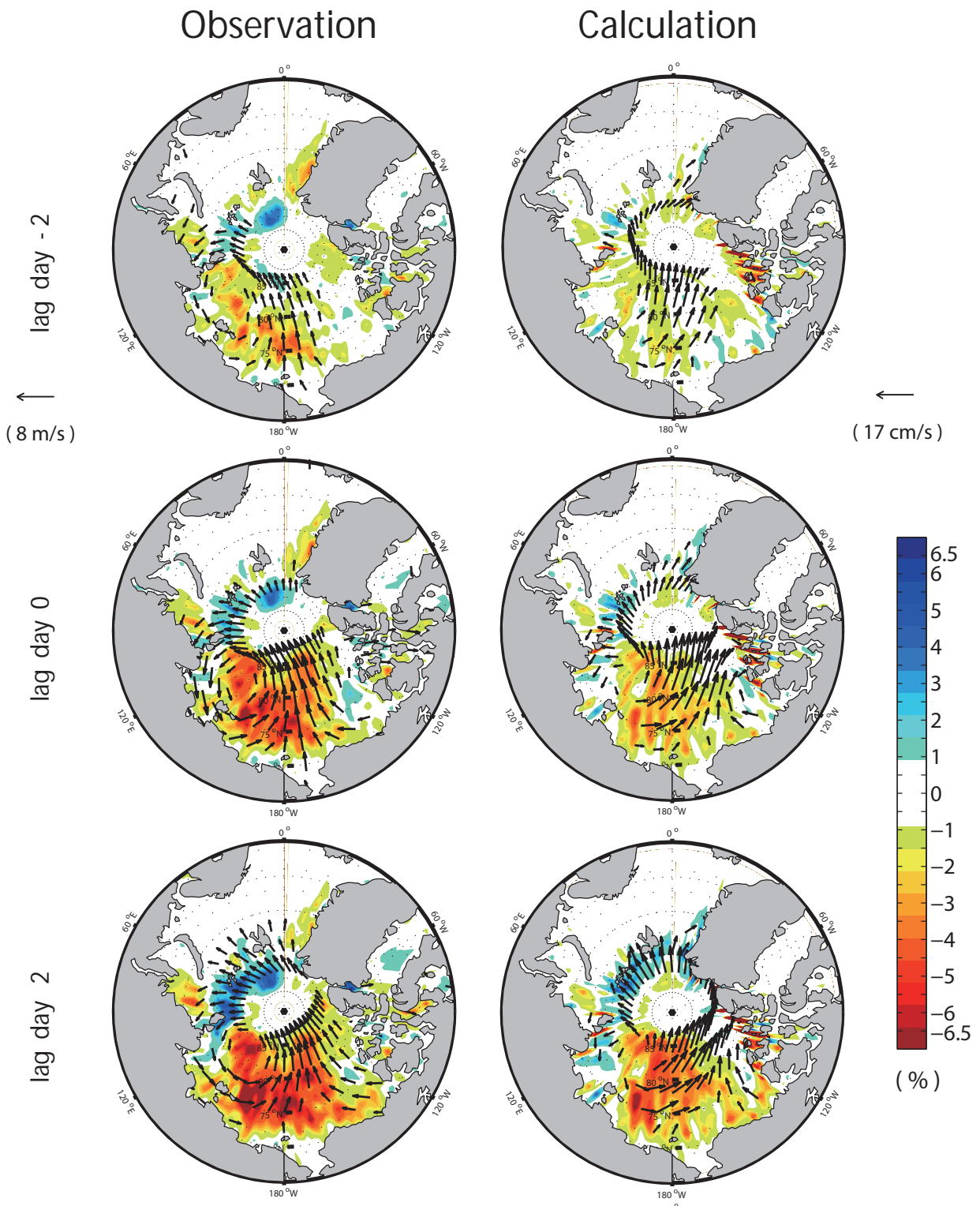

(\%)
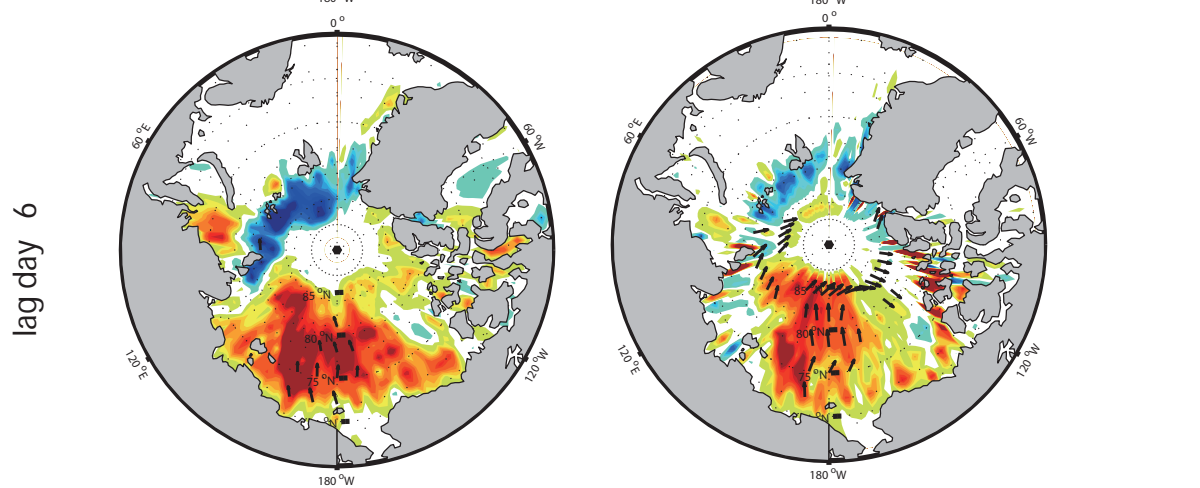

Figure 8. Composites of the anomalous sea ice concentration (\%) calculated from NSIDC satellite observations (left column panel) and from our analytical model using ERA-Interim $10 \mathrm{~m}$ wind velocity data (right column panels) for lag -2 days (first row panels), 0 days (second row panels), 2 days (third row panels), and lag +6 days (fourth row panels). See Sect. 5 for a full description of this calculation. Vectors indicate the anomalous $10 \mathrm{~m}$ winds from reanalysis $\left(\mathrm{m} \mathrm{s}^{-1}\right.$; left column panels) and calculated sea ice velocity ( $\mathrm{cm} \mathrm{s}^{-1}$; right column panels). For the anomalous $10 \mathrm{~m}$ winds (left column panels) and sea ice velocity (right column panels), only vectors stronger than $1.5 \mathrm{~m} \mathrm{~s}^{-1}$ and $3.0 \mathrm{~cm} \mathrm{~s}^{-1}$ are plotted, respectively. 


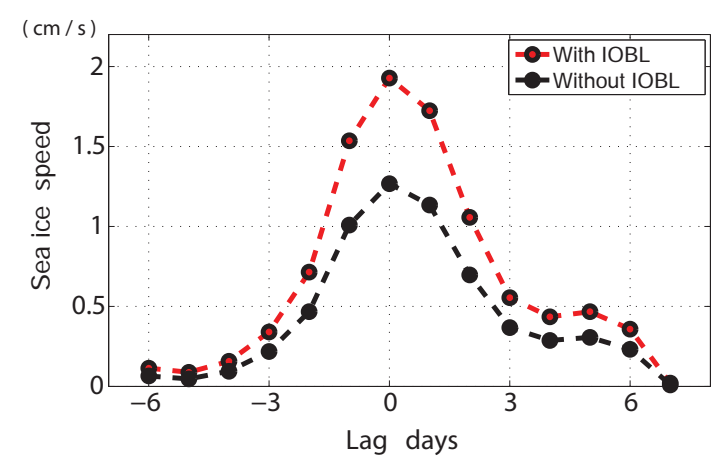

Figure 9. Lagged composite of the calculated sea ice speed $\left(\mathrm{cm} \mathrm{s}^{-1}\right)$ associated with the strong southerly events in the presence (red line) and in the absence (black line) of an IOBL in our analytical model (in the absence of an Ekman layer the ocean surface velocity is simply set to 0 - the classical free drift case). The sea ice speed is area-averaged over the Pacific sector of the Arctic (from 150 to $230^{\circ} \mathrm{E}$ and from 70 to $90^{\circ} \mathrm{N}$ ). The sea ice speeds include the surface Ekman layer (red line) identical to those used to construct Fig. 8. The dimensionless vertical diffusivity is set to $K_{\mathrm{O}}^{*}=0.028$ and $K_{\mathrm{O}}^{*}=\infty$ for the IOBL (red line) and no-IOBL (black line) cases, respectively.

man layer velocity were sufficiently weak compared to the ice velocity then we could simply neglect the ocean velocity altogether. As introduced in Sect. 4, the "classical" free drift (zero Ekman layer velocity) corresponds mathematically to the limit of infinitely large vertical diffusivity $\left(K_{\mathrm{o}}^{*} \rightarrow \infty\right)$ in our model. In Fig. 9 we compare the anomalous sea ice speed associated with the wind-induced ice drift with and without an IOBL included in the model. Both curves have been generated by averaging the sea ice speed anomalies over the Pacific sector of the Arctic (from 150 to $230^{\circ} \mathrm{E}$ and from 70 to $90^{\circ} \mathrm{N}$ ) and then calculating lagged composites across all southerly wind events. Consistent with Fig. 3a, this plot illustrates that the IOBL increases the wind-induced sea ice speed up to $40-50 \%$. We therefore conclude that the IOBL plays a substantial role in the rapid reduction of SIC associated with strong southerly wind events.

\section{Summary and discussion}

In this study we have derived an analytical model for windinduced sea ice drift and evaluated our model against measurements from a velocity sensor-equipped ice-tethered profiler. We then used the model to demonstrate that Arctic southerly wind events can drive substantial reductions in SIC over short timescales.

Our model has elements in common with Rossby similarity theory (McPhee, 2008) for the IOBL but differs crucially in the respect that it allows for an arbitrary mixture of ice and open water. The key features of this model are as follows.
1. The ice floes and leads containing open water are described via a bulk "mixture layer", momentum balance, following Gray and Morland (1994).

2. The IOBL consists of an Ekman layer whose depth is assumed to depend linearly on the surface stress velocity (McPhee, 2012), most appropriate for a neutrally stratified IOBL with no surface buoyancy flux (McPhee and Morison, 2001).

3. The transfer of momentum between the $10 \mathrm{~m}$ winds, the ice and ocean components of the mixture layer, and the ocean surface layer are assumed to follow a quadratic drag law. By contrast Rossby similarity theory assumes the "law of wall" to hold in a narrow boundary layer at the top of the IOBL (McPhee, 2008).

Though the simplicity of our model carries several caveats, discussed below, it also confers several advantages. As mentioned in the introduction, the analytical tractability of the model makes it very efficient, certainly much more so than running a fully coupled model of the Arctic. This makes it straightforward to interpret the model; the analytical expressions in Sect. 2 yield physical insight into the velocity observations from ITP-V 35 and the SIC data from NSIDC. The model's "mixture layer" formulation (Gray and Morland, 1994) also makes it suitable for the marginal ice zone. Our analytical approach was possible because we assumed a constant vertical diffusivity in the surface Ekman layer. This simplification results in an IOBL turning angle $\left(\theta_{\mathrm{IOBL}}\right)$ that is independent of ice-ocean stress $\boldsymbol{u}_{\mathrm{io}}^{*}$ in our model, whereas the turning angle slightly decreases as the ice-ocean stress strengthens in observations (McPhee, 2008). It may be possible to extend our model to incorporate Rossby similarity theory and a stratified IOBL, but for SICs below $100 \%$ the surface boundary condition must be modified to account for the presence of patches of open water between the ice floes.

A shortcoming of our model is that it neglects internal stresses in the ice, which can feature prominently in the momentum balance when the SIC is close to $100 \%$ (Leppäranta, 2005). The model is therefore only formally applicable for SICs below $\sim 85 \%$. In this article we have frequently used the case of $100 \% \operatorname{SIC}(\varphi=1)$ for the purpose of illustration, as the model solution is qualitatively unchanged for SICs greater than $\sim 50 \%$.

Our analytical model qualitatively reproduces the windinduced ice speed and wind-ice velocity angles in the ITP$\mathrm{V} 35$ observations. The agreement is improved by replacing the canonical value $K_{\mathrm{o}}^{*}=0.028$ of the vertical eddy diffusivity with an enhanced value of $K_{\mathrm{o}}^{*}=0.1$. However, this finding should not be interpreted to mean that the enhanced diffusivity is more physically relevant. While the discrepancy between the model and observations may be due to stronger turbulent mixing due to surface buoyancy loss, it is more likely due to impedance of the sea ice motion by internal stresses, 
as the SIC in the vicinity of the ITP-V 35 observations was likely around $85-90 \%$.

We applied our analytical model to investigate the strong southerly events in the Arctic summer to estimate the windinduced reduction of SIC. The calculated reduction of SIC is largely consistent with satellite observations. Our results verify that the southerly wind-induced sea ice drift can substantially decrease SIC over the course of a week. Because the wind-induced sea ice drift can be directly calculated from our analytical solution, the underlying processes for the sea ice variability might be better identified by utilizing reanalysis data. We suggest that our analytical model can be a flexible tool for identifying and quantifying the mechanisms for the Arctic and Antarctic sea ice cover variability, which is often associated with the changes in the global-scale circulation pattern (Lee et al., 2011; Holland and Kwok, 2012; Bitz and Polvani, 2012; Li et al., 2014; Wettstein and Deser, 2014; Raphael and Hobbs, 2014; Park et al., 2015). 


\section{Appendix A}

In this appendix we estimate the ice-ocean drag coefficient, $C_{\mathrm{io}}$, using the ITP-V data. The ITP-V was programmed to record turbulent fluctuations at $6 \mathrm{~m}$ depth for $40 \mathrm{~min}$ on a daily basis. As noted by Cole et al. (2014), $C_{\text {io }}$ can be estimated by the relationship between ice-ocean velocity shear and turbulent momentum flux:

$\sqrt{{\overline{u^{\prime} w^{\prime}}}^{2}+{\overline{v^{\prime} w^{\prime}}}^{2}}=C_{\mathrm{io}}\left[\left(u_{\mathrm{i}}-u_{6}\right)^{2}+\left(v_{\mathrm{i}}-v_{6}\right)^{2}\right]$.

Here the overbar $\overline{()}$ denotes a $40 \mathrm{~min}$ time average and the primes ()$^{\prime}$ denote deviations from the time mean. The ice and $6 \mathrm{~m}$ ocean velocities are denoted as $\left(u_{\mathrm{i}}, v_{\mathrm{i}}\right)$ and $\left(u_{6}, v_{6}\right)$, respectively. Using Eq. (A1), we calculated daily $C_{\text {io }}$ from the ITP-V data, following Cole et al. (2014). In Fig. A1 we plot $C_{\text {io }}$ as a function of the surface wind speed and the surface stress. These plots support our approximation of the iceocean quadratic drag coefficient as a constant, $C_{\mathrm{io}}=0.0071$. Estimates of the IOBL quadratic drag coefficient $C_{\mathrm{d}}$, obtained by setting $u_{6}=v_{6}=0$ in Eq. (A1) under the assumption that the interior geostrophic velocity is negligible, are qualitatively similar to those shown in Fig. A1 (not shown).
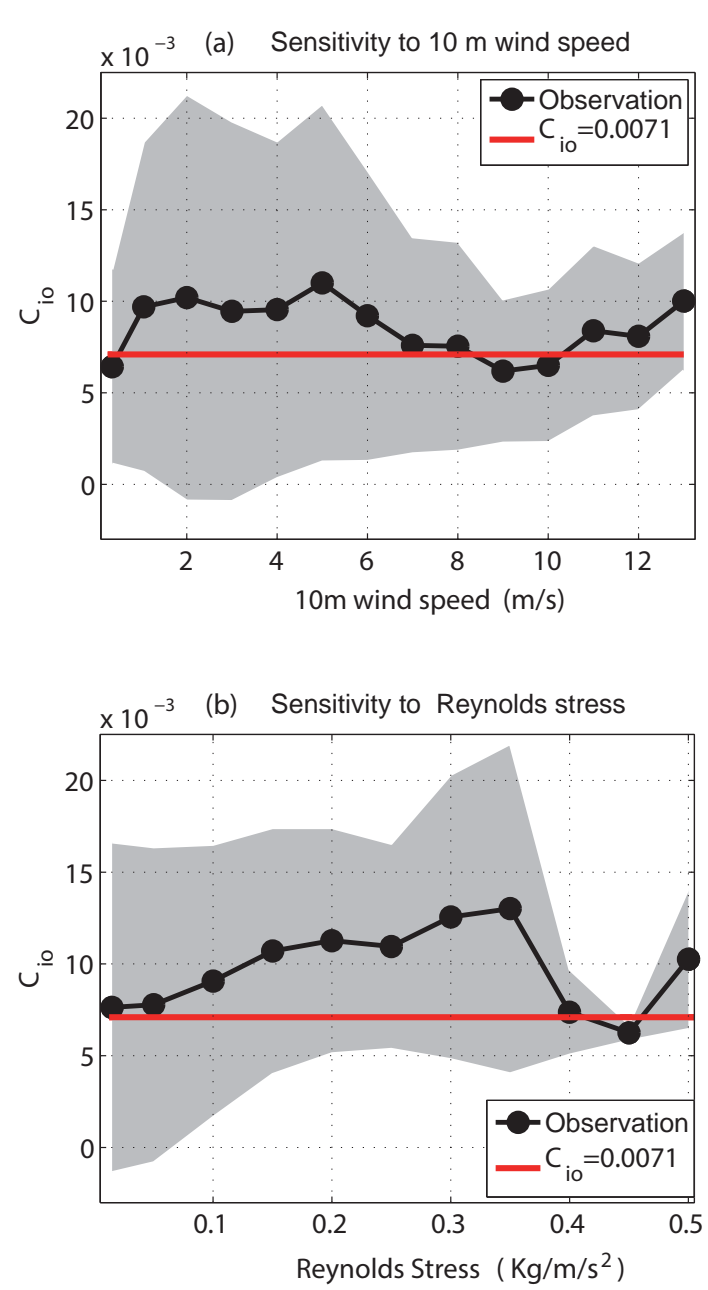

Figure A1. Sensitivity of the ice-ocean drag coefficient $C_{\text {io }}$ to (a) the surface wind speed $\left(\mathrm{m} \mathrm{s}^{-1}\right)$ and (b) the surface stress $\left(\mathrm{kg} \mathrm{m}^{-1} \mathrm{~s}^{-2}\right)$, calculated using Eq. (A1). The black line shows the mean value calculated from ITP-V 35 observations and the gray shadings indicate the range of 1 standard deviation from the mean. The red line corresponds to the value estimated by Cole et al. (2014) based on least-squares approximation. 
Author contributions. A. L. Stewart and H.-S. Park developed the analytical model for wind-driven drift of sea ice. H.-S. Park conducted analyses and prepared figures. Both authors contributed equally to writing the manuscript.

Acknowledgements. H.-S. Park would like to thank S. Lee, S.-W. Son, Y. Kosaka, and S. Feldstein for helpful comments and discussions. The authors thank three anonymous reviewers for detailed comments that were particularly helpful for improving the manuscript. H.-S. Park was supported by the Basic Research Project of the Korea Institute of Geoscience and Mineral Resources (KIGAM) funded by the Ministry of Knowledge Economy of Korea. A. L. Stewart was supported by the University of California, Los Angeles, USA. The authors thank John Toole and Sylvia Cole for assistance with the ITP-V 35 observational data set.

Edited by: L. Kaleschke

\section{References}

Bitz, C. M. and Polvani, L. M.: Antarctic Climate Response to Stratospheric Ozone Depletion in a Fine Resolution Ocean Climate Model, Geophys. Res. Lett., 39, L20705, doi:10.1029/2012GL053393, 2012.

Bitz, C. M., Fyfe, J., and Flato, G.: Sea ice response to wind forcing from AMIP models, J. Climate, 15, 522-536, 2002.

Cole, S. T., Timmermans, M-L., Toole, J. M., Krishfield, R. A., and Thwaites, F. T.: Ekman Veering, Internal Waves, and Turbulence Observed under Arctic Sea Ice, J. Phys. Oceanogr., 44, 13061328,2014

Dee, D. P., Uppala, S. M., Simmons, A. J., et al.: The ERA-Interim reanalysis: Configuration and performance of the data assimilation system, Q. J. Roy. Meteorol. Soc. 137, 553-597, 2011.

Gray, J. M. N. T. and Morland, L. W.: A two-dimensional model for the dynamics of sea ice, Philos. T. Roy. Soc. Lond. A, 347, 219-290, 1994.

Heorton, D. B. S., Feltham, D. L., and Hunt, J. C. R.: The Response of the Sea Ice Edge to Atmospheric and Oceanic Jet Formation, J. Phys. Oceanogr., 44, 2292-2316, 2014.

Hibler III, W. D.: A dynamic thermodynamic sea ice model, J. Phys. Oceanogr., 9, 815-846, 1979.

Holland, P. R. and Kwok, R.: Wind-driven trends in Antarctic sea ice drift, Nat. Geosci., 5, 872-875, 2012.

Johnson, M., Proshutinsky, A., Aksenov, Y., Nguyen, A., Lindsay, R., Haas, C., Zhang, J., Diansky, N., Kwok, R., Maslowski, W., Hakkinen, S., Ashik, I., and de Cuevas, B.: Evaluation of Arctic sea ice thickness simulated by Arctic Ocean Model Intercomparison Project models, J. Geophys. Res., 117, C00D13, doi:10.1029/2011JC007257, 2012.

Kawakuchi, Y. and Mitsudera, H.: A numerical study of ice-drift divergence by cyclonic wind with a Lagrangian ice model, Tellus A, 60, 789-802, 2008.

Lee, S., Gong, T. T., Johnson, N. C., Feldstein, S. B., and Pollard, D.: On the possible link between tropical convection and the Northern Hemisphere Arctic surface air temperature change between 1958-2001, J. Climate, 24, 4350-4367, 2011.
Leppäranta, M.: The Drift of Sea Ice, Springer-Verlag, Berlin, 2005.

Li, X., Holland, D. M., Gerber, E. P., and Yoo, C.: Impacts of the north and tropical Atlantic Ocean on the Antarctic Peninsula and sea ice, Nature, 505, 538-542, 2014.

Liptak, J. and Strong, C.: The winter atmospheric response to sea ice anomalies in the Barents Sea, J. Climate, 27, 914-924, 2014.

Lüpkes, C. and Birnbaum, G.: Surface drag in the Arctic marginal sea ice zone: a comparison of different parameterisation concepts, Bound.-Lay. Meteorol., 117, 179-211, 2005.

Lüpkes, C., Gryanik, V. M., Hartmann, J., and Andreas, E. L.: A parametrization, based on sea ice morphology, of the neutral atmospheric drag coefficients for weather prediction and climate models, J. Geophys. Res., 117, D13112, doi:10.1029/2012JD017630, 2012.

McPhee, M. G.: The effect of the oceanic boundary layer on the mean drift of pack ice: Application of a simple model, J. Phys. Oceanogr., 9, 388-400, 1979.

McPhee, M. G.: An analytic similarity theory for the planetary boundary layer stabilized by surface buoyancy, Bound.-Lay. Meterol., 21, 325-339, 1981.

McPhee, M. G.: On the turbulent mixing length in the oceanic boundary layer, J. Phys. Oceanogr., 24, 2014-2031, 1994.

McPhee, M. G.: Air-ice-ocean interaction: turbulent ocean boundary layer exchange processes, in: chapters 4 and 9, Springer, New York, 2008.

McPhee, M. G.: Advances in understanding ice-ocean stress during and since AIDJEX, Cold Reg. Sci. Technol., 76, 24-36, 2012.

McPhee, M. G. and Morison, J. H.: Under-ice boundary layer, in: Encyclopedia of Ocean Sciences, Elsevier, Academic Press, New York, 3069-3076, 2001.

Park, H.-S., Lee, S., Son, S.-W., Feldstein, S. B., and Kosaka, Y.: The impact of poleward moisture and sensible heat flux on Arctic winter sea ice variability, J. Climate, 28, 5030-5040, 2015.

Plueddemann, A. J., Krishfield, R., Takizawa, T., Hatakeyama, K., and Honjo, S.: Upper ocean velocities in the Beaufort Gyre, Geophys. Res. Lett., 25, 183-186, 1998.

Randelhoff, A., Sundfjord, A., and Renner, A. H. H.: Effects of a Shallow Pycnocline and Surface Meltwater on Sea Ice-Ocean Drag and Turbulent Heat Flux, J. Phys. Oceanogr., 44, 21762190, 2014.

Raphael, M. N. and Hobbs, W.: The influence of the large-scale atmospheric circulation on Antarctic sea ice during ice advance and retreat seasons, Geophys. Res. Lett., 41, 5037-5045, doi:10.1002/2014GL060365, 2014.

Schweiger, A., Lindsay, R., Zhang, J., Steele, M., Stern, H., and Kwok, R.: Uncertainty in modeled Arctic sea ice volume, J. Geophys. Res., 116, C00D06, doi:10.1029/2011JC007084, 2011.

Serreze, M. C., Maslanik, J. A., Scambos, T. A., Fetterer, F., Stroeve, J., Knowles, K., Fowler, C., Drobot, S., Barry, R. G., and Haran, T. M.: A record minimum arctic sea ice extent and area in 2002, Geophys. Res. Lett., 30, 1110, doi:10.1029/2002GL016406, 2003.

Smith, R. D., Dukowicz, J. K., and Malone, R. C.: Parallel ocean general circulation modeling, Physica D, 60, 38-61, 1992.

Sorteberg, A. and Kvingedal, B.: Atmospheric forcing on the Barents Sea winter ice extent, J. Climate, 19, 4772-4784, 2006.

Sumata, H., Lavergne, T., Girard-Ardhuin, F., Kimura, N., Tschudi, M. A., Kauker, F., Karcher, M., and Gerdes, R.: An intercompar- 
ison of Arctic ice drift products to deduce uncertainty estimates, J. Geophys. Res.-Oceans, 119, 4887-4921, 2014.

Swift, C. T. and Cavalieri, D. J.: Passive microwave remote sensing for sea ice research, Trans. AGU, 66, 1210-1212, 1985.

Thorndike, A. S. and Colony, R.: Sea ice motion in response to geostrophic winds, J. Geophys. Res., 87, 5845-5852, 1982.

Toole, J. M., Timmermans, M.-L., Perovich, D. K., Krishfield, R. A., Proshutinsky, A., and Richter-Menge, J. A.: Influences of the ocean surface mixed layer and thermohaline stratification on Arctic sea ice in the central Canada Basin, J. Geophys. Res., 115, C10018, doi:10.1029/2009JC005660, 2010.

Uotila, P., O'Farrell, S., Marsland, S. J., and Bi, D.: A sea ice sensitivity study with a global ocean-ice model, Ocean Model., 51, 1-18, 2012.

Wettstein, J. J. and Deser, C.: Internal Variability in Projections of Twenty-First-Century Arctic Sea Ice Loss: Role of the LargeScale Atmospheric Circulation, J. Climate, 27, 527-550, 2014.
Williams, A. J., Thwaites, F. T., Morrison, A. T., Toole, J. M., and Krishfield, R.: Motion tracking in an acoustic point-measurement current meter, Proc. OCEANS 2010 IEEE, Sydney, Australia, IEEE, 1-8, doi:10.1109/OCEANSSYD.2010.5603862, 2010.

Wu, B., Wang, J., and Walsh, J. E.: Dipole anomaly in the winter Arctic atmosphere and its association with sea ice motion, J. Climate, 19, 210-225, 2006.

Zhang, J., Lindsay, R., Schweiger, A., and Steele, M.: The impact of an intense summer cyclone on 2012 Arctic sea-ice retreat, Geophys. Res. Lett., 40, 720-726, doi:10.1002/grl.50190, 2013.

Zhang, J. and Rothrock, D. A.: Modeling global sea ice with a thickness and enthalpy distribution model in generalized curvilinear coordinates, Mon. Weather Rev., 131, 681-697, 2003. 